REVISTA DE DERECHO UNED, NÚM. 8, 2011

\title{
UN MODELO EN TRANSICIÓN: PRÁCTICA FORENSE Y LEGALISMO DECIMONÓNICO
}

\author{
Carlos Tormo Camallonga \\ Profesor Titular Universitat de València-Estudi General
}

Resumen: La fundamentación de la sentencia y la alegación en derecho por las partes responden a la misma concepción del proceso y de la administración de justicia. El cambio en su materialización acontece en España a lo largo de las décadas centrales del siglo XIX; en materia civil, tomando como referencia la Instrucción del Marqués de Gerona de 1853 y la Ley de Enjuiciamiento Civil de 1855. Pero la realidad práctica de los tribunales tenía sus propios tiempos, diferentes para jueces y abogados. Si la nueva redacción de la sentencia provocará disquisiciones legales y resistencias entre las instancias judiciales, con los escritos de las partes no sucederá lo mismo. Éstos irán esquivando las históricas prohibiciones de una manera más lenta y velada. En este artículo veremos cómo evoluciona el discurso letrado a propósito de un destacado pleito testamentario que a mitad del siglo se tramita en la Audiencia de Valencia.

Palabras clave: Fundamentación de la sentencia, apuntamientos, memoriales de hecho, alegaciones en derecho, discurso jurídico, autos, apelación, Instrucción del Marqués de Gerona, Ley de Enjuiciamiento Civil.

Abstract: The foundation of the judgment and the juridical allegations obey to the same change in the conception of the judicial procedure. It happens in Spain throughout the central decades of the 19th century; in civil matter, taking as reference the Instrucción del Marqués de Gerona, in 1853, and the Ley de Enjuiciamiento Civil, in 1855 . But the practical reality of the courts had his own times, different for judges and attorneys. If the change in the formulation of 
the judgment causes legal disquisitions and resistances of the judicial instances, with the writings of the parts the same thing will not happen. They will avoid the historical prohibitions in a slower and more silent way. In this article we will see the evolution in the layers' speech with a testamentary lawsuit in the middle of the nineteen century, in the Audiencia of Valencia.

Key words: Motivation of the judgment, notes, briefs of facts, allegations in right, juridical speech, judicial procedure, appeal, Instrucción del Marqués de Gerona, Ley de Enjuiciamiento Civil.

Sumario: I. Planteamiento de la cuestión. II. Informes en derecho. III. Testamentaría de la duquesa de Almodóvar. III.1.Sobre sucesión en el vínculo de D. Cristóbal Cardona. III. 2. Sobre sucesión en el vínculo de D. Carlos Ramírez de Arellano. IV. Breve epílogo.

\section{PLANTEAMIENTO DE LA CUESTIÓN}

La motivación judicial y la aportación explícita de la norma jurídica positiva al proceso por parte del letrado, obedecen a un mismo cambio en la sustanciación procedimental, en su alcance y comprensión y, por extensión, en el paradigma de la administración de justicia. Entendemos que acontece en España a lo largo de las décadas centrales del siglo XIX; en materia civil, en concreto, podemos tomar como referencia la Ley de Enjuiciamiento Civil de 1855, con el destacado precedente de la Instrucción del Marqués de Gerona de 1853. Sin embargo, la realidad práctica de los tribunales no parece ir de la mano, al menos no tan estrechamente, de las permisiones o prescripciones contenidas en éstas y en otras normas. Cierto es que la situación de abogados y jueces no será exactamente la misma; no estarán sujetos a la misma responsabilidad ni supervisión exterior, como tampoco su posición ni posicionamiento dentro del organigrama judicial serán los mismos. Si el cambio en la formulación de la sentencia, es decir, la exigencia de su fundamentación, originará disquisiciones parlamentarias y legales -pocas y sin mucha relevancia, eso sí- y, sobre todo provocará resistencias por parte de las instancias judiciales, con el cambio en los escritos de las partes no sucederá lo mismo. Así se aprecia, por ejemplo, en los informes que al respecto de la Instrucción del Marqués de Gerona remiten al Ministerio de Justicia las audiencias, juzgados y colegios de abogados. ${ }^{1}$

\footnotetext{
${ }^{1}$ Por requerimiento del artículo 102 de la Instrucción; Archivo de la Comisión General de Codificación, legajo 3, carpeta 2, documento 2.
} 
En este artículo nos acercaremos al estilo con que los abogados del XIX irán esquivando el viejo axioma del iura novit curia, a través de los procesos tramitados en la audiencia de Valencia, así como de los apuntamientos y de las alegaciones jurídicas en su relación con el proceso. Y todo ello a propósito de un destacado pleito que a mitad de este siglo se estaba tramitando en sus salas, como fue el de la testamentaría de la Duquesa de Almodóvar².

La situación del proceso de principios de siglo, que es el que tomamos como punto de partida, apenas muestra diferencias respecto a la tradición heredada; no se observa cambio ni evolución significativa en la forma, en el contenido y en la redacción de los escritos procesales de los letrados, caracterizados, entre otras cosas, por su estilo argumentativo exclusivamente fáctico. De contener expresiones que pudiéramos considerar como estrictamente jurídicas, no pasarían de ser, «como dice la ley del reyno» o, a lo sumo, «la ley recopilada»; poco más. Tampoco las resoluciones judiciales, y no sólo las sentencias, muestran diferencia alguna con respecto a las del siglo anterior; son igualmente escuetas, mínimas: «se confirma con costas el auto apelado», "se confirma la sentencia», o «no ha lugar a la suplicación»; también sin más.

Con el paso del tiempo se va abriendo una clara tendencia hacia el cambio, con una formulación y un estilo más conciso y directo por parte de los letrados, y con una creciente aportación de citas jurídicas, tampoco especialmente llamativa, pero sí evidente; un estilo y unas aportaciones ausentes en los escritos de décadas anteriores. Si se seguía sin permitir al abogado decir el derecho, tal y como se concebía históricamente, sí al menos se le deja apuntarlo³. Aunque

${ }^{2}$ Archivo del Reino de Valencia (ARV), Escribanías de Cámara (EC), 1854, núm. 19.

${ }^{3}$ Tanto para las citas de las partes como para las sentencias, puede consultarse cualquier proceso de estos años en la sección Escribanías de Cámara del ARV. Algunos procesos, como decimos, empiezan a mostrar signos de cambio. Así por ejemplo, uno de 1810 (EC, núm. 7), sobre nulidad de testamento, es inusitadamente prolijo en referencias jurídicas, como «la terminante disposición de la ley del Reyno», «permitido en la Ley de Toro», «nuestras patrias y reales leyes», «dicha ley real» (sin haberse recogido en autos ley alguna), «según previene la Real Pragmática cuya excepción oponían» (sin contener de nuevo los autos pragmática alguna), e incluso «el eminentísimo cardenal» $\mathrm{y}$ «los autores ritualistas». Es posible que en este caso y otros similares se aluda a disposiciones alegadas anteriormente y de forma oral, de ahí que no se individualizasen, intentando cumplir con las prohibiciones legales. Sobre esto último, en otro pleito de 1812 (Escribanías de Cámara, núm. 48) se contienen expresiones tales como: «porque si se hubiese atenido a la disposición literal de la Ley de Partida...», y "para resolverlo así no es necesario más que tener a la vista la ley que habla 
estamos ante una metamorfosis de difícil contrastación empírica, cuantitativa si se quiere, la lectura de los procesos nos lleva indefectiblemente a esta percepción y, si se me permite, conclusión, lo que ya es evidente a mediados de siglo. Con el paso de los años se profundiza en el uso, que hasta entonces no había hecho más que divisarse o intuirse, de referenciar y dejar constancia por escrito de las disposiciones sobre las que, al parecer, las partes estaban discutiendo y alegando en el pleito oralmente. Incluso, se llega a copiar literalmente el contenido de alguna ley, sin decir de cuál se trataba, lo que en sí ya era realmente novedoso, por venir prohibido por la legislación histórica y también por la que en estos momentos se estaba aprobando en otras materias, como la mercantil. Pero, por ser prácticas no regladas, la mayoría de procesos, y aún posteriores, seguirán obedeciendo a los esquemas tradicionales ${ }^{4}$. Un paso más en este proceso evolutivo será la referencia explícita e individualizada de dispo-

en este negocio y reconocer...». Y sobre lo mismo, en otro pleito de 1818, sobre revalidación de testamento ( $E C$, núm. 7$)$, se dice «por el mismo principio de ley natural que lo es también regla de derecho, las palabras y ley de Partida en que se apoya el contrario». En un pleito de 1815, sobre nulidad de testamento (EC, núm. 24), asistimos a una mayor individualización si cabe: en primera instancia se menciona una bula «corroborada y reconocida por el Rey Católico Dn. Carlos Tercero ... que solicitó de su santidad el papa Pío Sexto, para que se permitiese a los frayles que sirven de capellanes en los exércitos disponer entre vivos y en última voluntad de lo que adquiriesen en razón de tales destinos, cuya gracia se concedió en diez de febrero de mil setecientos ochenta y quatro», para continuar en el ramo de la Audiencia con «ninguno de los autores de Sagrados Cánones, Leyes patrias ni la práctica inconcusa...». También se individualiza más en otro pleito de 1828 , sobre donación y vinculación (EC, núm. 28), con las siguientes expresiones: "porque es contraria a la Ley recopilada, reputándose por tales, según la ley de Partida, las que se oponen a la honestidad, buenas costumbres, obras de piedad y al derecho»; «Si estos hechos son innegables nada más se necesita que examinar la ley para decidir si el difunto Vicente Garcés los pudo practicar. Está dispuesto por Real Cédula del año 1789 que en adelante no se pueda prohibir perpetuamente la enagenación de bienes raíces o estables por medios directos o indirectos sin licencia del rey a consulta de la Cámara. Esta ley es cierta»; o «los mismos argumentos de que se ha valido desde el principio fundados en la ley recopilada que cita» (sin que con anterioridad se hubiera citado ninguna ley en concreto).

${ }^{4}$ Insistimos en lo dicho en la nota anterior. Es notorio un pleito de 1840 (EC, núm. 36), sobre pago de cantidad, en el que, sin explicitar norma en concreto, son continuas las expresiones del tipo "que la ley que se citaba»; "que la ley en que se apoyaba»; «la ley dice que se especifique por menudo qué es lo que se recibe y el precio porqué se recibe [...], que fue el objeto que el legislador se propuso al dictar las leyes referidas [...], con infracción tan manifiesta de leyes tan claras y terminantes»; "y la ley que se ha citado manda que en los contratos en que las partes se obliguen [...]. Estas son las literales palabras de la ley, y según se deja entender por ella habla ésta de cosas presentes»; «pues tal la declaran no sólo las leyes indicadas ya en estos autos, sí que otras varias de que no se ha hecho mérito por no creerlo necesario»; «dar a una de las leyes que declaran la nulidad del documento en que se apoyó su demanda la interpretación 
siciones, sin copiarlas o, incluso, también haciéndolo. En un principio se limitará claramente a las normas procesales, especialmente si eran recientes; después, se pasará también a las sustantivas ${ }^{5}$.

más contraria que pueda concebirse al espíritu de la ley»; «luego la ley ha sido quebrantada, la ley ha sido hollada [...]. Porque la ley nada indica de nulidad, discurren que subsiste la validez de la escritura: ora se infrinje la ley, ora se observe porque no encuentran la palabra nulidad en todo el texto de la ley». De nuevo, estas leyes citadas según estos extractos suponemos que, en su caso, lo habrían sido oralmente, pues en los autos no constan referenciadas por escrito. El siguiente extracto es, sin duda, más relevante y significativo, si cabe: «Incumbencia es, pues, de mi referido, el demostrar a Ferragud el error en que ha incurrido al hacer aplicable la ley que cita al presente caso, puesto que aunque sea cierta su disposición, también lo es que nada dice de nulidad, careciendo por lo tanto de todo apoyo y mérito legal los fundamentos que le sirven de base para pretender la nulidad del documento a que se refiere. Y para convencimiento de esta verdad no hay más que leer dicha ley y se verá que solamente se encuentra a su final la siguiente cláusula: Y para evitar fraudes todos los escritos ante quienes pasasen tales contratos lo hagan y cumplan así. De consiguiente, debemos concluir que no hablando dicha ley nada de nulidades y siendo esto nada más que una sencilla prevención hecha a los escribanos, la escritura es válida [...]. Según estas palabras literales de la ley ...». En otro momento se dice: «Parafraseando la primera excepción cita una ley que dice: Mandamos que de aquí adelante en los contratos en que las partes se obliguen por razón de mercadurías, se ponga y declare la mercaduría que se vende por menudo y estenso, por manera que se entienda qué es lo que se vende y el precio que se dé por ello. Y para evitar fraude mandamos a todos los escribanos ante quienes pasasen los tales contratos lo hagan y cumplan así. Por el contenido de esta ley infiere la parte contraria que faltándole a la escritura [...], el requisito legal que debe observarse [...] pero el error en que ha incurrido Salvador Ferragud, queriendo hacer aplicable la ley citada al caso presente es muy notorio, porque, aunque sea cierta su disposición, también lo es que nada dice de nulidades, careciendo por lo mismo de todo apoyo legal los fundamentos en que se apoya»; «Cita también una disposición recopilada, cuyo contenido se reduce a que [...]. Según se desprende por esta legal disposición, para que el documento público tenga fuerza de ejecutivo se requiere [...]. Cuando el legislador mandó guardar las referidas solemnidades ...». Y como venimos indicando, sigue sin señalarse ni individualizarse precepto alguno, ni siquiera el código en que se encuentran las citas, a pesar de que se hubieran copiado literalmente.

${ }^{5}$ En un pleito de 1840 sobre pago de cantidad (ARV, EC, núm 50), una de las partes defiende «hallarme en el artículo 27 que rige en la Ley de los Juicios de Paz, al capítulo $2^{\circ}[\ldots]$ conforme al espíritu de la Ley de Conciliaciones«. Sin embargo, en cuestiones sustantivas los escritos se limita a las tradicionales fórmulas «la ley marca» y similares, sin individualización alguna. En un pleito de 1853, sobre nulidad de diligencias de remate y venta de media casa (núm. 31), un abogado escribe sobre su cliente que «no fue tampoco citada para el remate con arreglo a la ley 12 , títu ${ }^{\circ} 28$, lib $^{\circ} 11$ N.R., que establece, bajo pena de nulidad, este requisito esencialísimo». El abogado contrario razona sobre la suplicación de una sentencia interlocutoria: «está espresamente dispuesto en la L. $1^{\text {a }}$, T. 21, L. 11 de la N. R. En ella se dice: que si de las sentencias interlocutorias ...». En el escrito de suplicación, este mismo abogado escribe: «A pesar de tan clara y justa sentencia, a pesar de que por lo dispuesto por la $\mathrm{L} 1^{\mathrm{a}}$. T $18 \mathrm{~L} 11$ de la N. R. no puede interponerse suplicación si se tratase de sentencia dada en algún incidente...». En similares términos puede verse un pleito de 1853, sobre 
Frente a esta evolución en los escritos de las partes, la configuración de las resoluciones judiciales a lo largo de estas décadas será exactamente la misma de antaño; nada cambiaba en su formulación. Juez y letrado tenían, pues, tiempos diferentes.

Ésta es la realidad de escritos y resoluciones durante la primera mitad del siglo. Pero la abundante legislación sustantiva que se venía aprobando en todos los sectores del ordenamiento jurídico, la confusión normativa que pudiera ocasionar respecto a viejas leyes -no confusiones respecto a éstas entre sí, cosa ya histórica-, y, en general, la progresiva consolidación de una nueva cultura positivista, entendemos que, todo ello conjuntamente, conformaría un estado de opinión entre los partícipes de la administración de justicia que, sino era claramente favorable a que el discurso letrado incorporara ya citas legales explícitas, al menos ya no resultaba tan frontalmente adverso. $\mathrm{Si}$, como dice Marta Lorente, «la búsqueda de la norma y la justificación de su vigencia resultaron ser las primeras, y muchas veces casi únicas, actividades científicas e interpretativas asumidas y desarrolladas por juristas y jueces isabelinos», ¿porqué no condescender y permitir la participación del letrado en esta búsqueda, siempre que no supusiera un ataque frontal a la autoridad a través del quebrantamiento de las normas recopiladas, cosa que vendría a ser, por ejemplo, la copia de citas textuales? ${ }^{6}$ De hecho, la misma legislación ya lo venía permitiendo, expresamente, en los procesos penal, mercantil y también administrativo y, precisamente, siempre que no se copiara literalmente la disposición ${ }^{7}$.

riego de campos (núm. 21), en donde, respecto comparecencias y términos, se citan, copian y comentan disposiciones de Partidas, Novísima y del Reglamento Provisional para la Administración de Justicia, además de recientes reales órdenes.

${ }^{6}$ LoREnTE SARIÑENA, M., «Justicia desconstitucionalizada. España, 1834-1868», De justicia de jueces a justicia de leyes: hacia la España de 1870, coord. Marta Lorente Sariñena, Cuadernos de Derecho Judicial, VI -2006, 245-287, p. 266.

${ }^{7}$ El artículo 1.213 del Código de Comercio de 1829, desarrollado en la Ley de Enjuiciamiento sobre Negocios y Causas de Comercio, de 24 de julio de 1830, pasa por ser la primera norma liberal en imponer la motivación de la sentencia, con una pretensión, la de ofrecer seguridad mercantil al inversor, ciertamente distante de lo que aquí discutimos (la mismas normas parece que también permiten a las partes alegar y argumentar en derecho durante el proceso). Pero es en el Derecho Administrativo en donde motivación y argumentación jurídica se asientan con mayor firmeza y menos problemas; artículo 16 de la Ley de Organización y Atribuciones de los Consejos Provinciales, de 2 de abril de 1845, y artículo 30 del Reglamento sobre el modo de proceder los Consejos provinciales como tribunales administrativos, y de su régimen interior, de 1 de octubre de 1845 . En cuanto a la materia penal, y tras los intentos fallidos de motivación procesal en el proyecto de código de procedimiento criminal de 1821 y de código penal del año siguiente, puede verse la regla primera de la Ley provisional prescribiendo la aplicación de las disposiciones del Código penal, de 19 de marzo de 1848. 
El poder y la autoridad ya no se personalizan en el juez de la misma manera que antaño, sino que éste se convierte en el intermediario entre el legislador y el ciudadano. La cita ya no se verá como un atentado contra aquél, contra su origen, en su concepción más soberana y originaria; pero tampoco contra la ley, que emanaba del mismo ciudadano. Era la participación del ciudadano en la administración de justicia. Paralelamente, y otro orden de cosas, pero desde la misma evolución socio-jurídica, las universidades también se estaban incorporando a este cambio de paradigma, con la reforma en sus planes de estudio y la incorporación decidida en ellos del Derecho positivo, en pro de una concepción de la justicia esencialmente administrativista, en virtud de la cual se consideraba al juez como un mero aplicador de la ley ${ }^{8}$.

Respecto al juzgador, sin embargo, las cosas parecen más sencillas pero más complejas al mismo tiempo. Más sencillas porque la mutación -la fundamentación jurídica- no podía venir dada por una simple inercia práctica, curial, por una simple permisión silenciosa por el resto de agentes judiciales, como parece introducirse en el actuar de los letrados. No era posible. Tenía que venir dada, necesariamente, por mandato legal e imperativo, lo que permitiría al juez tener un punto de partida; también a nosotros como estudiosos. Pero, sin embargo, y por esto decimos que la cuestión es al mismo tiempo más compleja, esta misma prescripción normativa no parece que resultara suficiente. Así se refleja en muchos de los procesos consultados en la audiencia de Valencia, en los que en este punto se hace caso omiso a los mandatos de la Ley de Enjuiciamiento Civil, cuando en el artículo 333 dice que «Las sentencias definitivas de todo artículo, y las de los pleitos, serán fundadas [...]. A continuación hará mérito en párrafos separados también, que empezarán con la palabra Considerando, de cada uno de los puntos de derecho fijados en los mismos escritos, dando las razones y fundamentos legales que estime procedentes, y citando las leyes o doctrinas que considere aplica-

\footnotetext{
${ }^{8}$ Nos referimos a una renovada formación universitaria, con unos planes de estudios que muestran una verdadera preocupación por acercarse al nuevo sistema normativo. PESET REIT, M., «Estudios de derecho y profesiones jurídicas», El tercer poder. Hacia una comprensión histórica de la justicia contemporánea en España, Frankfurt, 1992, págs. 349-380. Véase también Tormo CAMALlONGA, C., "L'advocacia durant la vigència del pla d'estudis de 1824», Aulas y Saberes, 2 vols., 2003, II, pp. 511-520; «Implantación de los estudios de Jurisprudencia en el Arreglo Provisional de 1836: el caso de la Universidad de Valencia», y "Los estudios y los estudiantes de Jurisprudencia y Teología tras la unificación de las facultades de Leyes y Cánones»; ambos en Cuadernos del Instituto Antonio de Nebrija de Estudios sobre la Universidad, 6 (2003), 221-254, y 8 (2005), 359-437, respectivamente.
} 
bles». Pues bien, la Audiencia dictará sentencias que, o bien seguirán exactamente el esquema anterior -no en muchas ocasiones, eso sí-, o bien se limitarán a la motivación exclusivamente fáctica, y, caso de ser jurídica, a la meramente procedimental, pero no sustantiva, lo que es mucho más aséptico y menos comprometido. Esto último es lo que mayormente sucede durante los años siguientes a la publicación de la LEC.

Claro está que no nos podemos contentar con la manida explicación de que, siendo la motivación la única o mejor manera de controlar el proceder correcto del juez y de exigirle su afección al régimen y, por tanto, responsabilidades, la inexistencia de un código claro y único invalidaba esta posibilidad. Porque, siendo cierto que uno de los grandes problemas con los que se va a encontrar todo jurista era el de la inexistencia de un código único en el que dar con la norma inequívocamente vigente para cada cuestión planteada en el foro, la afección al régimen no se aseguraba a través de la resolución del proceso, del sentido que le otorgaba el juez a la sentencia, sino que ya se había demostrado a través de mecanismos previos: su nombramiento y, en su caso, su movilidad, lo que no necesariamente vendría determinado por su actuación en el foro. La indispensable afección al régimen isabelino invalidaba cualquier consideración más allá de la estrictamente política. Así pues, no parece que la motivación fuera considerada como un medio de control sobre la judicatura. Al menos, no en estos momentos, porque esto ya se había logrado desde el mismo nombramiento. Sin embargo, podría considerarse que, llegados a este punto, la motivación sí dependería de lo avanzada que estuviera la codificación o la publicación de las nuevas normas, más claras y sencillas que la vieja legislación histórica. Aun así, esta posibilidad tampoco resulta del todo convincente en la medida en que la motivación en el proceso civil no esperó a la publicación del código, tras leyes sustantivas de indudable envergadura.

Respecto a esto último, la evolución en el proceder del letrado pasa por una explicación similar. En principio, lo más fácil es pensar que el que se le permitiera o no alegar norma jurídica explícita pasaba por la existencia de un código, o al menos de una legislación clara y concisa, y suficientemente completa y coherente. Andando el tiempo, en la medida en que el juez vaya adquiriendo caracteres funcionariales en el sentido más contemporáneo del término, progresivamente desligado de su naturaleza de súbdito histórico del monarca y pasándolo a ser de la nación, ya no se sentirá el mismo rechazo, como hemos dicho, ante el derecho del ciudadano particular a que, a través de su letrado, informe al juzgador acerca de la norma aplicable 
a cada caso. Tal vez el jurado pueda entenderse como un paso más en esta evolución.

Estamos ante una nueva concepción del poder que configura una nueva comprensión de la justicia, que termina por desmontar el viejo axioma del iura novit curia en su concepción más originaria y restrictiva. Y si la legislación civil, iusprivatista, fue la última en reconocer esta posibilidad, hemos dicho que, aunque fuera muy tenuemente, el cambio ya venía vislumbrándose de facto, al menos para las partes. Y aunque no pase por ser una explicación de envergadura, y a falta de estudios de mayor profundidad al respecto, intuimos que, ante todo, estamos frente una cuestión con un fuerte componente sociológico y, por qué no, personalista, a la vez que generalizable. Estamos hablando de un cambio, en el sentido de evolución, que difícilmente podría verificarse sino a través de un recambio generacional de unos protagonistas que, por su procedencia y formación, no siempre estarían suficientemente preparados para servir al y en el nuevo sistema ${ }^{9}$. Un cambio y regeneración, sin duda, más fácil y sencillo para los letrados que para los jueces, por ser el de aquéllos un colectivo con un filtro de pertenencia, en principio, más abierto e imparcial.

Hemos dicho que la evolución en los escritos de los letrados se produce de una manera paulatina, progresiva y sin aspavientos. De hecho, el Reglamento para la Administración de Justicia, de 1835, que en tantas ocasiones se ha tomado como referencia para marcar un antes y un después en la administración de justicia española, tiene un carácter esencialmente orgánico y, por ello, no contemplaba cambios procedimentales ni la relajación de las viejas prohibiciones en esta cuestión; tampoco respecto a la motivación de la sentencia. Más bien lo contrario, pues se remite a las leyes recopiladas ${ }^{10}$. Tam-

\footnotetext{
${ }^{9}$ Pedro Gómez de la Serna y Juan Manuel Montalbán, en un ataque cerrado a la inmotivación judicial, argumentaban: «no podemos menos de censurar enérgicamente una disposición que se opone a las buenas doctrinas, y que puede dar lugar a que a su sombra se comentan grandes abusos en la administración de justicia [...], el razonamiento de las sentencias pone en claro la ilustración o la ignorancia del juez, hace más fácil y espedita su responsabilidad, le obliga a estudiar con más esmero el litigio, y es finalmente una garantía poderosa de la rectitud y del acierto de los fallos»; Tratado Académico-Forense de Procedimientos Judiciales, 2 vols, Madrid, 1848, I, pág. 304.

${ }^{10}$ Art. $4^{\circ}$ : «En la sustanciación de los negocios civiles y criminales deberán también todos los jueces, bajo su responsabilidad, observar y hacer que se observen con toda exactitud los sencillos trámites y demás disposiciones que las leyes recopiladas prescriben para cada instancia, según la clase del juicio o del recurso, sin dar lugar a que por su inobservancia se prolonguen y compliquen los procedimientos o se causen indebidos gastos a las partes; sobre lo cual en adelante no podrá servir de excusa a los jueces ninguna práctica contraria a la ley».
} 
poco las normas procedimentales civiles habían previsto o contemplado novedad alguna en el proceder de los letrados. El decreto de las Cortes Sobre sustanciación de los pleitos de menor cuantía de 1837, nada había dicho al respecto, como tampoco la Instrucción del Marqués de Gerona de 1853, reguladora del juicio de mayor cuantía ${ }^{11}$. Es más, de nuevo son reiteradas las remisiones a las leyes recopiladas.

Hay que esperar a la Ley de Enjuiciamiento Civil de 1855 para encontrar una disposición inequívoca: «El juicio ordinario principiará por demanda, en la cual, expuesto sucintamente y numerados los hechos y los fundamentos de derecho, se fijará con precisión lo que se pida, determinando la clase de acción que se ejercite, y la persona contra quien se proponga» (art. 224). Pero, aun así, no es inocuo que la ley de bases de 13 de mayo de 1855 recogiera como primera pretensión restablecer en toda su fuerza las reglas cardinales de los juicios, consignadas en nuestras antiguas leyes, en donde no se hablaba, precisamente, de las aportaciones o citas jurídicas. Si para los jueces las bases prescribían de manera categórica, y como novedad general en todos los procesos, «que las sentencias sean fundadas», nada prefijaban, por el contrario, para los argumentos en derecho de las partes, que finalmente sí se incluyeron en el articulado. Hubiera sido relevante que lo hubieran hecho si consideramos que aquellas reglas cardinales de los juicios, consignadas en nuestras antiguas leyes, no permitían precisamente estas defensas jurídicas. Indudablemente, era un tema de menor relevancia, una novedad accesoria, respecto a la sentencia. Y si estas discordancias entre los nuevos mandatos y la legislación histórica permitieron a los jueces sortear la motivación prescrita por la Ley de Enjuiciamiento Civil, en su formulación más rigurosa, la argumentación explícitamente jurídica no parece que a estas alturas planteara oposición o impedimento alguno. La LEC no hizo más que sancionar una situación que de hecho ya venía permitiéndose, ordenándola y exigiéndola ahora desde el mismo escrito de la demanda. Es más, respecto a las discordancias a que hemos hecho referencia entre la Ley de Enjuiciamiento y la legislación histórica, en lo que a estos trámites se refiere, lo bien cierto es que la doctrina que en su momento comentó esta ley tampoco mostraba un discurso muy elaborado, sino más bien pobre. En todo caso la interpretaba desde las disposiciones recopiladas, reproduciendo las mismas y vie-

${ }^{11}$ Aunque el artículo 63 de la Instrucción pueda dar lugar a diversas interpretaciones, nada indica que incluyese una licencia en favor del letrado para escribir en Derecho. 
jas vaguedades ${ }^{12}$. Y puesto que las prescripciones de la Ley no resultaban en esto fácilmente compatibles con aquel realce de las leyes recopiladas, durante los siguientes años convivieron ambos modelos; al menos, es lo que hemos observado en la práctica procesal en la Audiencia de Valencia, que creemos generalizable al resto de audiencias.

\section{INFORMES EN DERECHO}

Si el cambio en los escritos procesales responde a un tránsito tranquilo, sin planteamientos a priori -quién sabe si, incluso, fuera de toda percepción y pretensión consciente por parte de los mismos abogados-, esta transformación tendrá su correlato en los informes en derecho o alegaciones jurídicas. Pero se verificará en sentido inverso. En la medida en que aquellos escritos se juridifiquen, en la medida en que los letrados expongan leyes y construcciones normativas, estas alegaciones finales perderán su histórica transcendencia e incluso su propia razón de ser. Al menos, ya no serán tan relevantes si entendemos que las argumentaciones jurídicas, además de las fácticas, ya se habían ido aportado ante la Audiencia a lo largo de los escritos procesales previos.

Aunque muchos de estos informes sigan resultando escritos largos y farragosos, ya no se nos muestran tan reiterativos en sus razonamientos. Tampoco resulta fácil ver esa pretensión erudita, incluso literaria, que en tantas ocasiones apreciábamos en las alegaciones del siglo pasado; ese estímulo para que también sirvieran de ejemplo y modelo para otros procesos futuros semejantes.

Recordemos que, en cuanto a su presentación y según Novísima 5 , 1, 31, «no se den informaciones de derecho salvo en el pleyto que a los magistrados les pareciere ser necesarias, lo qual declaren luego que se acabare de ver el pleyto ${ }^{13}$. Es decir, la sala concedería el per-

${ }^{12}$ Véase José de Vicente y Caravantes, Vicente Hernández de la Rúa, o Pedro Gómez de la Serna y Juan Manuel Montalbán, que se aportan en otros apartados de este estudio. El primero de ellos llegaba a aportar argumentos tan simples y endebles como «que las razones que impulsaron a prohibir que se fundaran las sentencias consistían principalmente en el poco acierto y mal método de su redacción y gastos a que esto daba lugar; con las disposiciones de la nueva ley que prescriben un método sencillo y breve de redactarse los motivos del fallo, han desaparecido aquellos inconvenientes»; Tratado histórico, crítico filosófico de los procedimientos judiciales en materia civil, según la nueva Ley de Enjuiciamiento, con sus correspondientes formularios, 3 vols., Madrid, 1856-1858, I, pág. 115.

${ }^{13}$ En el caso del Consejo, Novísima Recopilación 4, 8, 5, establece un plazo para entregar las informaciones de dos meses «después que el tal pleyto y proceso fuere 
miso atendiendo a la importancia pecuniaria del objeto de litigio o a la relevancia de las cuestiones jurídicas debatidas. Ni la legislación histórica permitía presentarlas en las causas menores, ni tampoco el Decreto de cortes sobre sustanciación de los pleitos de menor cuantía, de 10 de enero de 1837. Así pues, y en principio, es una vez conclusos y vistos los autos para definitiva, cuando la sala decidiría admitir la petición de redacción y presentación de las informaciones. Para esta petición la legislación no reservaba ningún trámite ni momento concreto, pero la lógica procesal nos hace entender que se presentaría junto o después de los escritos de conclusión para definitiva. Tampoco queda claro si la autorización para escribir y presentar alegaciones se concedía al final pero en la misma vista definitiva, después de ella, o en una vista incidental y convocada al efecto. En cualquier caso, los escritos en derecho no corresponden estrictamente al proceso, que ya se haya concluso, "y si fuere pedido, sean puestos en fin del dicho pleyto», como dice Novísima. Por todo ello, el proceso no tenía porqué contener referencia alguna a ellos ${ }^{14}$.

Así es que, dado que la dispersa legislación histórica apenas se había ocupado de las alegaciones, era la costumbre curial, diversa y variada según la audiencia, la que venía a rellenar este vacío. De manera que los cambios que se produjeran en la práctica decimonónica, tampoco tendrían que plantear grandes objeciones ${ }^{15}$. Y si magistrados y abogados eran conscientes de estar ante realidades difusas y de incierto futuro, no creemos que plantearan inconvenientes a traspasar unos usos que ya no tenían el mismo valor de antaño, máxime en unos escritos cada vez menos frecuentes. La práctica, de nuevo, se adelantaba a la teoría (arts. 873 y siguientes de la LEC) ${ }^{16}$.

visto en Consejo». Véase una descripción de estos escritos y su evolución en Castilla, en Coronas GonZÁLEZ, S. M., "Alegaciones e Informaciones en Derecho (porcones) en la Castilla del Antiguo Régimen», Anuario de Historia del Derecho Español, 73 (2003), 165-192.

${ }^{14}$ Novísima Recopilación, 11, 14, 1. J. Febrero, Librería de escribanos, abogados y jueces, 5 vols., Madrid, 1819, IV, pág. 303, y Conde de la Cañada, Instituciones prácticas de los juicios civiles, así ordinarios como extraordinarios, en todos sus trámites, según que se empiezan, continúan y acaban en los tribunales reales, 2 vols., Madrid, 1794, I, pág. 180.

${ }^{15}$ Alonso Romero, $\mathrm{M}^{\mathrm{a}} \mathrm{P}$., «Las reglas de juego: herencia procesal y constitucionalismo», De justicia de jueces a justicia de leyes: hacia la España de 1870, Cuadernos de Derecho Judicial, núm. 6 (2006), 209-242.

${ }^{16}$ Tormo CAmallonga, C., «El fin del ius commune. Las alegaciones jurídicas en el juicio civil de la primera mitad del XIX», Anuario de Historia del Derecho Español, 71 (2001), 473-500. A pesar de lo arriba dicho, y a falta de un mayor examen de esta cuestión, las alegaciones del siglo XIX que hemos consultado para las audiencias de Valencia y Barcelona no nos permiten concluir que efectivamente se asiste a una 
Por lo que respecta a su contenido estrictamente jurídico, se asistirá, y esto sí es relevante, a un cambio radical. El histórico ius commune y ese acumulativo mos italicus tardío de que hasta ahora venían impregnadas, se sustituye en el XIX por una defensa jurídica mucho más breve, concisa y escueta. El cambio es completo. Además, las pocas citas jurídicas que se aporten ahora serán mayoritariamente de leyes sustantivas nacionales. Y llama aquí la atención el que dejen paso no sólo a las normas sustantivas más recientes, sino sobre todo a las históricas de Partidas y Novísima, que son estos momentos cuando más se alegan, mucho más que en el siglo anterior. Aunque parezca algo contradictorio, no es así, puesto que los derechos privados, la propiedad fundamentalmente, que es lo que mayormente se debate en las alegaciones jurídicas, sigue siendo la misma. Y desde la desaprobación del nuevo sistema jurídico hacia la doctrina, los viejos códigos legales castellanos seguían manteniendo todo su prestigio y renombre, al menos por lo que respectaba a la funcionalidad de estos escritos.

Pero nos encontramos ahora con apuntes que resultarían imposibles en las alegaciones del siglo anterior. Del pleito que analizaremos a continuación hemos hallado dos alegaciones jurídicas, en una de las cuales el abogado se permite la expresión siguiente: «Dejando para los discursos de academia la legislación romana y de Partidas acerca de la significación de hijo natural según ellas, debemos concretarnos a la legislación vigente», para a continuación citar una ley de Novísima y otra de Toro. Más adelante cita una ley de Partidas, y en ningún caso aporta legislación romana ni doctrinal, lo que es una grandísima diferencia respecto a alegaciones pretéritas, máxime si consideramos que se está discutiendo una cuestión hereditaria ${ }^{17}$.

evolución lenta y progresiva en su forma y contenido. Desde la información que poseemos, estaríamos, más bien, ante un cambio más marcado y notorio, y sin apenas transición. Es, no obstante, una cuestión sobre la que algún día tendremos que volver.

${ }^{17}$ Alegación en Derecho por D. José Caro y Baciero, como padre y legal administrador de D. Miguel Caro y Baciero, en el pleito con D. José Guerau de Arellano..., Arxiu Històric de la Col.legiata de Xàtiva, Processos, C-389 ter, P 1.006. La otra alegación que hemos encontrado de este pleito se construye desde su fundamentación en diversas leyes de Partidas, a las que se acompañan otras de las de Toro y, en este caso sí, algunas citas doctrinales, respecto a estas leyes, de autores exclusivamente castellanos. Véase Alegación por doña Leonor Fortuny, viuda y heredera de D. Salvador María Cardona, en el pleito que sigue con la testamentaría de la duquesa de Almodóvar..., Valencia, 1854, Biblioteca Valenciana, NP34/F339. Igual de escueta en cuanto a su contenido jurídico es otra alegación jurídica, de un pleito diferente, pero también sobre herederos testamentarios. Se ciñe a la ley de 27 de septiembre de 1820 , restablecida por la de 30 de agosto de 1836, sobre fideicomisos, a la de capellanías de 19 de agosto de 1841 , y a la recopilada 20 , título 5 , libro $1^{\circ}$. También aporta una decisión del 
Cosa diferente pero estrechamente ligada a las alegaciones jurídicas era el apuntamiento. No nos referimos al memorial recopilatorio de los autos de primera instancia con que se iniciaba la apelación ante la Audiencia, después de la fórmula «Al relator para la formación del apuntamiento», o semejante, sino al memorial ajustado a los hechos o relación concertada con las partes, que también redacta el relator y presenta ante la sala una vez conclusos los autos para definitiva. Se entiende que a la vista definitiva el relator debía acudir con este memorial de los hechos, aunque es posible que los oidores pudieran consultarlo ya con anterioridad. Su redacción era ineludible cuando la cuantía de la demanda superaba los cinco mil maravedís o cuando, siendo menor, así lo consideraba la sala; caso de no estimarlo oportuno, el relator narraba lo acontecido en autos simplemente de palabra ${ }^{18}$. A diferencia de los alegatos de bien probado, propios e interesados según la parte que los presentaba, en esta relación concertada el relator proporciona a la sala una narración de los hechos pactada y refrendada por procuradores y abogados ${ }^{19}$. Si las alegaciones jurídicas no forman parte estrictamente del proceso, este memorial de hechos sí. Por ello no hemos encontrado legajo alguno al que se adjunten las alegaciones, mientras que es habitual encontrar cosidos los apuntamientos impresos ${ }^{20}$.

La importancia del memorial radica en que es sobre sus hechos concertados sobre los que se redactarían, en su caso, las alegaciones jurídicas. Presentadas éstas al relator, éste las cotejaba con aquellos

Tribunal Supremo de 14 de diciembre de 1848, y referencias genéricas sobre los fueros de Toledo y Cáceres, así como «peticiones de las Cortes de Segovia, Madrid, Valladolid y Toledo». La doctrina y las citas romanas están completamente ausentes. Véase Alegación en Derecho por los hijos y herederos testamentarios de Josefa Alzamora en los autos sobre los bienes de la Administración que a favor de su alma fundó don Francisco Juan Alzamora, Valencia, 1864, Archivo Ilustre Colegio Abogados de Valencia (AICAV), I-2769.

${ }^{18}$ Novísima Recopilación 5, 1, 31 y 5, 23, 6. No sabemos si al relator se le concedía un determinado tiempo para redactar el memorial de las causas civiles (en Novísima sí se recogía un máximo para las fiscales; $5,23,10$ ).

${ }^{19} \mathrm{El} \mathrm{nombre} \mathrm{de} \mathrm{los} \mathrm{procuradores} \mathrm{y} \mathrm{los} \mathrm{abogados} \mathrm{aparece} \mathrm{ya} \mathrm{en} \mathrm{la} \mathrm{contraportada}$ del apuntamiento, con sus firmas en la última página. Y puesto que se redacta conclusos los autos, contiene numerosas remisiones a las hojas del legajo que previamente le ha entregado el escribano de la causa.

${ }^{20}$ A continuación de los asientos de la vista de este proceso, encontramos la siguiente anotación, que todo indica ser del tasador: «Por el reconocimiento y apuntamiento (el cotejo del mismo duró cinco horas), copias de árbol y papel con la extensión de sentencia a su tiempo, derechos excepto los del cotejo que corresponden a la testamentaría, quinientos diez y siete reales vellón»; ARV, Escribanías de Cámara, 1854, núm. 19, fol. 307v. 
hechos. No era conforme a la lógica procesal que se permitiera escribir el apuntamiento antes de concluidos los autos, ni mucho menos imprimirlo ${ }^{21}$. Tampoco hemos encontrado norma que exigiese su impresión, si bien, en su caso, estaría en función de las alegaciones. Tampoco está claro que éstas tuviesen que presentarse necesariamente impresas, lo que ya era una práctica generalizada desde el siglo anterior. Y como sucede con los informes en derecho, la práctica de los tribunales para los memoriales es mucho más variada de lo que establece, confusa y parcamente de nuevo, la normativa, y no siempre parece que se presente acorde a ella ${ }^{22}$.

\section{TESTAMENTARÍA DE LA DUQUESA DE ALMODÓVAR}

Si en estos momentos pende ante la Audiencia de Valencia un proceso especialmente significativo a los efectos de nuestro estudio, éste es el de la testamentaría de la duquesa de Almodóvar y del marqués de Malferit, sobre un vínculo testamentario fundado en 1664. Eso sí, al hallarse en un legajo con distintos ramos deshilvanados, desordenados temporalmente y no siempre completos, nos ha resultado muy difícil recomponer la secuencia de las actuaciones. De hecho, hemos llegado a la conclusión de que nos encontramos ante dos procesos sobre la misma testamentaría, con orígenes y peticiones distintas y con litisconsortes que, además de numerosos, se entrecruzan. A mayor abundamiento, diversos fallecimientos y la falta de hojas intermedias, nos dificulta todavía más el seguimiento de los actores y de los mismos procesos.

Lo enrevesado de las causas origina, pues, tramitaciones largas y complejas -nada especial, por otra parte-, pero que ilustran muy provechosamente el procedimiento civil de mediados del XIX. Y resulta interesante no sólo por las citas jurídicas de los escritos de las partes, sino y especialmente, por el seguimiento de los sucesivos trá-

${ }^{21}$ Novísima Recopilación 5, 1, 31; 5, 23, 6; y 11, 14, 3. Las Ordenanzas para todas las Audiencias e islas adyacentes, de 19 de diciembre de 1835, establecían en su artículo 111 que «Si el procurador y el letrado de alguna de las partes solicitaren se haga cotejo de los apuntamientos que han de servir para la determinación definitiva de las causas y pleitos, se prestarán a ello los relatores, sin necesidad de acudir para este objeto a la Sala».

${ }^{22}$ Novísima Recopilación 11, 14, 2 y 3; mientras la primera ley permite presentarlas «impresas o de mano», la segunda parece exigirlas impresas. Tampoco son muy claras en esto las Ordenanzas para todas las Audiencias e islas adyacentes, de 19 de diciembre de 1835, en sus artículos 108, 109 y 110. 
mites; en concreto, de los apuntamientos y de las alegaciones jurídicas.

En cuanto a los escritos procesales, no son esporádicos los preceptos jurídicos referenciados; algunos de ellos con señalamiento de ley, título y libro, copiados literalmente, con entrecomillados incluidos, lo que substituía a las antaño vagas y genéricas referencias a «la ley del reino». Ninguna referencia a autores -no eran habituales más que, muy ocasionalmente, alguna cita harto genérica-, y muchas a Novísima, Partidas y Leyes de Toro, hasta el punto de que uno de los letrados intenta justificar sus continuas referencias a estas leyes. En línea de lo que hemos apuntado respecto a la nueva legislación, en alguna ocasión estas leyes se traen a colación al compás de algún precepto del reciente código penal, que, evidentemente, también se comenta e interpreta ${ }^{23}$.

Por lo que respecta a apuntamientos y alegaciones, ciertamente, no es nada habitual encontrarnos con unos procedimientos que expliciten de manera tan clara la ejecución de estos escritos, y la relación entre ellos y con respecto al proceso, incluso con citas jurídicas, lo que resulta, sino inaudito, sí del todo inusual. De hecho, el que escribe no había constatado en ningún pleito anterior conexión tan evidente e insistente. De ahí el valor de muchas manifestaciones que, por su relevancia, he considerado conveniente transcribir. Aun a pesar de que pudiera parecer excesiva la pormenorización de estos trámites, como excesivo el número de transcripciones que incluimos, entendemos que lo inusual y esclarecedor del caso lo aconseja.

Aunque la vigencia de la Instrucción del Marqués de Gerona coincide plenamente con la tramitación del pleito, no se le llega a aplicar en ningún momento, como tampoco la Ley de Enjuiciamiento Civil; ésta, en su caso, sólo hubiera cabido para los trámites finales de la instancia de suplicación ${ }^{24}$.

${ }^{23}$ ARV, EC, 1854, núm. 19, fols. 112, 224, 258, 334, 340, 446, del primer ramo, y fols. 23, 47, 65, 127, 163, del segundo. En ambos casos a título de ejemplo.

${ }^{24}$ La Disposición Transitoria del artículo 105 de la Instrucción establecía su vigencia para los pleitos iniciados después de su publicación, y «en los pendientes se aplicará solamente a la segunda instancia y recursos posteriores en todos aquellos pleitos en que aun no hubiere recaído sentencia definitiva del Juez de primera instancia». Si real decreto de 18 de agosto de 1854 suspendía la observancia de la Instrucción de manera completa, hasta el punto de que los pleitos pendientes debían continuar sustanciándose según las leyes recopiladas y demás disposiciones vigentes con anterioridad, poca aplicación pudo tener la Instrucción. Aun así, a principios de 1854 encontramos algunas sentencias, en recurso de apelación interpuesto a finales del año anterior, que muestran una nueva estructura de la sentencia en vistos, 


\section{III.1. Sobre sucesión en el vínculo de D. Cristóbal Cardona}

El primero de los procesos se inicia el 2 de mayo de 1843, y se resuelve por el juez de primera instancia de Valencia por sentencia de 28 de marzo de 1849, absolviendo a la testamentaría de la duquesa de Almodóvar. Recurrida la sentencia por los demandantes iniciales, se inicia la apelación con los alegatos de agravios de enero y marzo de 1850. En mayo de 1852, el administrador y albacea de la testamentaría, absuelto en primera instancia, solicitaba por boca del procurador José Dalmáu, que tanto por la índole y diversidad de las cuestiones que se ventilan en estos autos, como por la importancia de los bienes que se reclamaban, "parece procedente se concierte e imprima la relación para poder a su tiempo escribir en derecho» ${ }^{25}$. Eso sí, a costas comunes. Y ni mucho menos se ha celebrado todavía la vista definitiva.

El escrito plantea una doble petición: presentar «concierto e impresión de la relación» y «escribir en derecho». Obsérvese la fórmula, en este segundo ruego, "para poder a su tiempo». Las otras partes, especialmente las dos primeras, que son las que apelaron la sentencia, manifiestan pareceres diferentes según cada una de las peticiones:

Esta petición la creo improcedente por cuanto, si bien son los bienes de alguna consideración, no encuentro diversidad en las cuestiones, pues por el contrario son sencillas y claras, de modo que en un informe oral basta para que VE forme juicio de la justicia que asiste a mi principal, y por ello es harto infructuoso el que se concierte la relación para escribir en derecho.

$$
* *
$$

Yo, en uso del traslado que se me ha conferido, no puedo menos de oponerme a esta pretensión por el fin con que se intenta. Fúndase la testamentaría en la índole y diversidad de las cuestiones que se ventilan en estos autos y en la importancia de los bienes porque se litiga, pero lo cierto es que si bien la cuantía litigiosa puede decirse de alguna importancia, las cuestiones que se ventilan pueden fácilmente tratarse en un informe oral, y solo por él podrá VE formar un juicio exacto y completo

considerandos o resultando, incluyendo incluso algunas referencias jurídicas, lo que constituye una verdadera novedad dentro de la práctica procesal de la audiencia valenciana; ARV, Escribanías de Cámara, 1853, núms. 17 o 26. En cuanto a la LEC, por decreto de 5 de octubre de 1855 se fijaba su vigencia para todos los procesos iniciados a partir del primero de enero del año siguiente; para los pendientes el mismo día 5 de octubre las partes podían optar por acomodarse a la nueva regulación, siempre que lo pidiesen todas ellas, cosa que, todo indica, no sucedía.

${ }^{25}$ ARV, EC, 1854, núm. 19, fol. 271 del primer ramo. 
del derecho de las partes. Por ello, pues, el escribir en derecho es aquí del todo punto escusable e innecesario, y solo produciría crecidos e inútiles dispendios a las partes que VE está en caso de evitar.

El que estos [autos] sean de alguna cuantía no es razón bastante para escribir en derecho, mayormente cuando las cuestiones suscitadas en estos autos son tan claras y de tan fácil solución que bastará un informe oral para que VE se imponga del derecho de las partes, y aquel medio solo serviría en el presente caso para causar crecidos e inútiles dispendios a las mismas. No debiendo pues por la mía oponerme a la práctica del concierto del apuntamiento, procede y suplico a VE se sirva denegar la impresión del extracto, accediendo a la petición de que se practique el concierto del mismo ${ }^{26}$.

Sorprende que sea la parte que solicita la confirmación de la sentencia de primera instancia la que más interés muestra en presentar los escritos en derecho, en tanto que son las partes apelantes y sobre las que recae la defensa de la acusación principal las que, precisamente, se oponen. Pero lo que realmente merece nuestra atención de este proceso es la compleja relación que se traza entre los apuntamientos y las alegaciones. Ante una normativa tan parca y confusa como era la recopilada en este punto, ya hemos dicho que iba a ser la práctica de cada tribunal lo que, en beneficio de la lógica procedimental, terminaría por imponerse. También aquí, pues, se distinguía entre un ius commune y un ius proprium para cada audiencia.

Pues bien, los apelantes consideraban que el esclarecimiento de las cuestiones jurídicas era tan sumamente simple como para no requerir informaciones en derecho por escrito, sino que era suficiente con las defensas orales en la vista. Por ello tampoco se veía conveniente la redacción del apuntamiento, ni mucho menos su impresión. No obstante, una de las partes, desde el convencimiento de la superfluidad de las alegaciones jurídicas, considera que lo enrevesado de la causa sí aconsejaba el concierto de los hechos, aunque no su impresión. En esta línea debe ir el parecer de la Sala cuando, tratado este incidente en vista incidental de 4 de septiembre de 1852, con asistencia de procuradores pero no de abogados, decide: «Practíquese el concierto de la relación con asistencia de las partes e imprímase a costas de la que lo ha solicitado» ${ }^{27}$.

${ }^{26}$ ARV, EC, 1854, núm. 19, fols. 273, 275 y 277, respectivamente.

${ }^{27}$ ARV, Escribanías de Cámara, 1854, núm. 19, fol. 283. Los dos últimos párrafos del apuntamiento impreso dicen lo siguiente: «53. Por esta resultancia han alegado y concluido las partes, y conclusos los autos, citadas las mismas, se han llamado para 
Es decir, se pospone la decisión que entendemos principal, la de escribir en derecho, haciendo recaer las cargas de la impresión del memorial sobre la parte interesada. El que la impresión del apuntamiento tuviese que estar a expensas de la presentación de las informaciones en derecho, y el que, en principio, todo esto se tuviese que determinar por la sala en la vista final, conclusos los autos para definitiva, lo corrobora el mismo José Dalmáu en escrito de 10 de junio de 1853. Tal y como nos sorprendió en su momento, solicitando escribir en derecho, nos sorprende de nuevo retractándose de su petición: "Que sin embargo de haber solicitado el concierto e impresión de la relación con el fin de escribir en derecho, vista la oposición de los coligantes, con mira de no perjudicar a la testamentaría y sin que por ello se entienda que renuncia a su pretensión respecto a escribir en derecho, desiste por ahora de la impresión hasta que V.E. determine si ha lugar a escribir en derecho ${ }^{28}$. La respuesta contrariada de las otras partes no se hace esperar, especialmente y de nuevo, de las dos primeras ${ }^{29}$.

definitiva, habiéndose guardado las leyes del procedimiento y observado lo dispuesto en el Real decreto vigente sobre uso de papel sellado. 54. Y mandado practicar el concierto del apuntamiento e imprimir el mismo a solicitud y costas de la testamentaría de la duquesa de Almodóvar, se ha verificado dicho cotejo con citación de las partes e intervención de los abogados». No obstante, del acto de cotejo en sí no se deja constancia en el ramo de autos más que, al menos en este caso, de su tasación.

${ }^{28}$ ARV, EC, 1854, núm. 19, fol. 287.

${ }^{29}$ Obsérvese la información que aportan respecto al sentido y significado de la secuencia de apuntamientos y alegaciones jurídicas: «La pretensión de D. José Dalmáu es por cierto bien estraña si se atiende a que él fue el que solicitó el concierto de la relación y que después de la oposición formulada por todos los demás colitigantes la sala, sin embargo, se sirvió mandar la práctica del concierto de la relación con citación de las partes a costas de dicha testamentaría. La petición [...] es tan anómala e irregular que no se concreta a separarse de lo que ya solicitó y obtuvo, sino que quiere decida V.E. antes del concierto si se ha de escribir o no en derecho, lo que no puede ocurrir porque se dejaba sin efecto el decreto de cuatro de setiembre del año último. También resultaría que decretando V.E. escribir en derecho, había por precisión de cumplimentarse previamente el nombrado decreto y, por el contrario, si la sala no conceptuaba procedente el que se escribiera en derecho, nos encontraríamos entonces en el caso de discutir y decidir por V.E. si la suspensión que ahora se solicita había de pasar a ser separación con las costas, y como quiera que no corresponde la reclamación hecha por los motivos espresados, no debe darse lugar [...] No es esta la época de ocuparse D. José Dalmáu acerca de los beneficios que puedan reportar a la testamentaría; que debía haberlo hecho antes de pedir el concierto, y que ahora si con su proceder ha perjudicado los intereses de dicho su podatario, cúlpese a sí mismo, no trate de salvar su responsabilidad en detrimento de los demás colitigantes. Fuera más franca la pretensión de Dalmáu si se concretara únicamente a separarse del concierto y de escribir en derecho, obligándose a pagar las costas originadas desde fs. 271 en adelante.»; «Si la testamentaría sin ninguna restitución hubiera desistido en todas sus partes de su pretensión, obligándose a satisfacer las costas que con ella se habían ori- 
El 4 de octubre de 1853, después de celebrada nueva vista incidental con asistencia de procuradores y en este caso también del abogado de la testamentaría de la Duquesa, la sala decide, más coherentemente con la normativa y también con lo que debería ser la práctica forense que, "sin embargo de lo acordado en decreto de cuatro de setiembre del año último, se suspende la impresión de la relación hasta que se determine si ha lugar a que se escriba en Derecho». Pero, por si hubiera algún resquicio de duda, y después de concluir para definitiva, el 14 del mismo mes José Dalmáu se apresta a recordarle a la sala su voluntad e intención: «No habiendo desistido del pensamiento primero de escribir en derecho, si la sala lo estima conveniente y hallándose repetida la misma petición en los dos citados escritos, no debió quizás considerar necesario reproducirla, pero en el caso de que no fuera el mismo el juicio de la sala, convendrá se tenga por nuevamente formalizada la petición de escribir en derecho para que produzca a su tiempo los efectos oportunos» ${ }^{30}$.

Obsérvese de nuevo la fórmula «a su tiempo». Así las cosas, el 22 de octubre la sala se limita a posponer la decisión hasta la vista definitiva, reconduciendo la secuencia de los escritos a su lógica procesal: «Procédase a la vista del pleito como está mandado, y de la misma resultará si se ha de escribir en derecho». El 16 de diciembre se señala el 22 del mismo para celebrar la vista de los autos principales. Al día siguiente, el procurador de una de las partes demandantes y ahora apelantes, Antonio Ayala, decía que «el asunto es grave y por consecuencia las alegaciones habrán de ser estensas, mayormente cuando se ha reclamado escribir en derecho y V.E. lo tiene reservado para definitiva, y es cuasi seguro que aún invirtiendo todas las horas de tribunal no podrá terminarse la vista en los dos días veinte y dos y veinte y tres, únicos en que podía realizarse antes del día del nacimiento del Señor ${ }^{31}$. Por ello, suplicaba la suspensión de la vista hasta nuevo señalamiento.

ginado, nosotros nos hallanaríamos a que V.E. accediera a ese desestimiento, ya que entonces no nos causaba ningún perjuicio notable, pero cuando se desiste tan solo de una parte de la pretensión y esto se hace con la salvedad de por ahora, no podemos menos de resistir el que V.E. acceda a ello.»; "Su representante después de haber transcurrido siete meses ha presentado el escrito de fol. 287 en el que solicita se suspenda por ahora la impresión de la relación hasta que V.E. determine si ha lugar a escribir en derecho [...] justo es que ahora se respete un decreto que tiene el carácter de ejecutorio y que por tanto las partes no pueden dejar de cumplir.» ARV, Escribanías de Cámara, 1854, núm. 19, fols. 289, 295 y 297, respectivamente.

${ }^{30}$ ARV, EC, 1854, núm. 19, fol. 301.

${ }^{31} \mathrm{ARV}, E C, 1854$, núm. 19, fol. 305. 
Entendemos que las alegaciones a que se refiere este escrito en su inicio son las que el abogado iba a aportar oralmente, las únicas de contenido jurídico que tradicionalmente eran permitidas (Novísima $11,14,1)$, si bien el procurador deja entrever que la sala ordenará también las escritas. Admitida la petición, el 17 de enero se señala para la vista definitiva el 23, prolongándose los días 24 y 27. Duran más de una hora, más de dos y menos de una, respectivamente, con asistencia de abogados y procuradores, además de escribano, portero y alguacil. Concluida la vista, el día 28 la sala concede permiso a las partes para escribir en derecho por término de treinta días, «imprimiéndose dentro del mismo la relación, como está mandado; y transcurrido, entregada o no al relator la relación impresa y las alegaciones, dese cuenta» ${ }^{32}$.

Como veremos en la siguiente causa, sería más acertado en términos de seguridad procesal separar el plazo del concierto de los hechos del de las alegaciones, por lo que el 20 de febrero de 1854 el procurador Ayala presenta una petición más que comprensible:

Este plazo es sumamente angustioso, puesto que si generalmente se concede en otros casos, tiénese ya en ellos impreso el extracto, y los interesados no sólo pueden escrivir sobre él sin necesidad de tener los autos a la vista, sino que hacen sus citas con la oportuna referencia a los números del extracto, y ahora por el contrario han de escrivir sobre los autos que todos quieren tener en su poder y ninguno puede citar el extracto porque ninguno lo tiene a la vista. Esta consideración es muy importante, porque si en realidad hay necesidad de escrivir en derecho, como la Sala lo ha declarado, parece muy conforme a justicia que se facilite a los interesados los medios de realizarlo conforme a las Leyes. Un escrito en derecho exige quando menos después de una detenida meditación, que se redacte, que se corrija, que se cotege por el Relator, y que obtenga la autorización del Presidente de la Sala antes que pueda hir a la prensa, y allí se ha de componer, tirar y enquadernar, y para todas estas partes hay concedidos más de treinta días.

Por fin el abogado que (sic) se halla en cama hace tres días, y es seguro que no saldrá de ella en dos o tres más sin que antes de este acontecimiento hubiera podido concluir sus trabajos, razón de más para que V.E. se sirva conceder una prórroga al plazo prefixado.

En esta atención, suplico a V.E. se sirva conceder diez días más de término para escrivir en derecho ${ }^{33}$.

${ }^{32}$ ARV, EC, 1854, núm. 19, fol. 308. Si bien Novísima 5, 1, 31, fijaba treinta días para presentar las alegaciones jurídicas -que no los memoriales- desde que fuere visto el pleito, el Reglamento Provisional para la Administración de Justicia establecía: «deberá darse la sentencia dentro de sesenta días improrrogables, contados desde el de la vista, preséntense o no las informaciones de las partes».

${ }^{33} \mathrm{ARV}, E C, 1854$, núm. 19, fol. 309. Obsérvese que se dice que el relator debe cotejar las alegaciones y el presidente de la sala autorizar su impresión. 
A dicha petición accede la sala, pero el 11 de marzo insiste de nuevo Ayala con otra petición; ahora en relación al número de hojas y extensión de las alegaciones:

En efecto, la alegación se está imprimiendo en la actualidad, pero en consideración a que no puede tener más de veinte líneas en la llana del sello y veinte y quatro en las otras, no es posible que pueda sugetarse a las veinte hojas de impresión y, por consiguiente, si se cumple con la Ley del papel sellado no es posible sugetarse a lo que anteriormente se hallaba establecido. Por esta misma razón ya en otro Pleyto seguido en esta Sala entre el Conde de Castellar y don Pedro de Albornós, se declaró que debían sugetarse los escritos en derecho a la Ley del papel sellado, y de lo contrario no se podría atender a la defensa de las partes en los términos que la Ley apetece. Por tanto, suplico a V.E. se sirva acordar se me admita la alegación en derecho en el número de foxas en que resulte extendido ${ }^{34}$.

Consideramos que se trata de una petición un tanto singular en la medida en que, al menos en la Audiencia de Valencia y durante el siglo anterior, el exceso de hojas era, no ya algo frecuente, sino norma general. El caso es que en similares términos se expresarán inmediatamente los procuradores de las otras partes, tanto de los coapelantes como de la parte apelada apelada (esta última, el segundo párrafo en el siguiente orden):

Que la ley recopilada fijaba en veinte el número de las fojas que podían contener las alegaciones en derecho, pero no tasaba el de líneas que hubiera de contener cada una. Mas como el decreto sobre uso del papel sellado ha fijado en 20 y 24 líneas las que respectivamente puede contener cada foja de papel sellado obliga en las alegaciones impresas a usar tipos mayores para evitar la deformidad que resultaría de tan corto número de líneas impresas, y por ello es ya muy difícil encerrar una alegación en derecho impresa en el número de fojas que fijaba la ley recopilada. En atención pues a la dificultad de cumplir con ambas disposiciones hasta cierto punto inconciliables, ha sido indispensable dar a la alegación de mi parte alguna más extensión de la que permite la ley recopilada, por lo que, suplico a V.E. se sirva acordar se admita la referida alegación a pesar de exceder algo de las 20 fojas que prescribe la ley recopilada.

${ }^{34}$ ARV, EC, 1854, núm. 19, fol. 312. En Novísima 11, 14, 2, se establecía un límite de dos informaciones en derecho en una instancia, con un máximo de 20 y 12 hojas, respectivamente. Véase en nuestro caso la Alegación por doña Leonor Fortuny, viuda y heredera de D. Salvador María Cardona... que, fechada el 6 de marzo de 1854, consta de 59 páginas de 24 líneas por el verso y 20 por el recto. Cada dos páginas de recto consta la anotación «lugar del sello en la edición oficial». 
Mas como quiera que ha sido preciso sujetarse al número de líneas, ha venido ha resultar un número mayor de hojas de veinte y no siendo posible evitarlo, suplico a V.E. se sirva acordar la admisión del escrito en derecho con el número de fojas en que ha resultado impreso.

$$
* *
$$

Como quiera que en la impresión se haya tenido que observar lo prevenido en la ley, concretándose a las líneas de veinte por la parte del sello y veinte y quatro al dorso, de ahí, pues, el escederse del numero de fojas prevenido, por lo tanto habiendo en consideración lo espuesto, espero y, suplico a V.E. se sirva admitir dicho escrito en derecho no obstante pasar del numero de fojas marcado ${ }^{35}$.

La sala resuelve el 14 de marzo: «Como se pide en los anteriores escritos [los dos primeros], repártanse por el Relator las alegaciones y relación impresas, y se señala para la votación de este pleito el día veinte y cuatro del actual ${ }^{36}$. Pero, dado que la tercera de las anteriores peticiones se había presentado con posterioridad, la sala pospone la votación para el 19 de abril ${ }^{37}$. Mientras tanto, el 31 de marzo se señalaba para la vista de esta discordia el 3 de abril, con asistencia de procuradores pero no abogados, sin que nos conste que se tomase decisión alguna sobre dicho exceso de hojas.

Queda claro que la vista definitiva, con la asistencia de abogados, se ha celebrado dos meses antes, sin la previa redacción ni consulta de las alegaciones jurídicas. Presentadas éstas se procede a la votación y resolución. La sala primera de la Audiencia dicta sentencia el 25 de abril de 1854, confirmando la de primera instancia y absolviendo a la testamentaría de la duquesa ${ }^{38}$. La sentencia no in-

${ }^{35}$ ARV, Escribanías de Cámara, 1854, núm. 19, fols. 314, 316 y 318, respectivamente.

${ }^{36}$ ARV, Escribanías de Cámara, 1854, núm. 19, fol. 317v.

37 «Repártanse por el Relator las alegaciones en derecho y apuntamiento impreso, y se señala para la votación el día diez y nueve del actual»; ARV, Escribanías de Cámara, 1854, núm. 19, fols. 317 y 321. Es una secuencia que, ciertamente, no queda suficientemente clara.

38 «En el pleyto que ante Nos pende en grado de apelación entre [...] sobre [...], habiéndose observado en la sustanciación los términos legales. = Vistos: = Fallamos que debemos absolver y absolvemos a la testamentaría de la Duquesa de Almodóvar y al Marqués de Malferit en cuanto pueda interesarles de la demanda propuesta por Don Salvador Cardona y continuada por su viuda y heredera D. ${ }^{a}$ Leonor Fortuny y D.Raymundo Mosi como marido de D. ${ }^{a}$ Salvadora Medina y padre de D. Joaquín Mosi y Medina, herederos de D. ${ }^{a}$ Joaquina Cardona; imponemos a los mismos silencio perpétuo en dicha demanda y dejamos salvos a la espresada testamentaría y al referido Marqués los derechos que a los bienes de que en estos autos se trata puedan corresponderles. En lo que sea conforme con la presente sentencia el definitivo del Juez de primera instancia de esta Ciudad de veinte y ocho de Marzo de mil ocho 
cluye motivación fáctica ni jurídica alguna, ni mucho menos referencia a las alegaciones. Y a pesar de la absolución de la testamentaria, tanto esta parte como las restantes presentan sus respectivas súplicas. Después de los oportunos escritos, Ignacio Torres, procurador de la parte que se había allanado y adherido al recurso de suplicación, manifiesta:

Que está ya tan agotada la discusión en estos autos, sobre todo desde que en las alegaciones en derecho que se imprimieron para la vista cada parte dio a sus respectivas razones toda la extensión de que son susceptibles, que sólo a fuerza de rebuscar puede hallarse alguna nueva razón o, más bien, algún nuevo punto de vista de las que anteriormente se han expuesto [...]. Poco hay que añadir acerca de esto a lo que tan repetidas veces hemos contestado, sobre todo en nuestra alegación de derecho ${ }^{39}$.

De nuevo, las palabras pueden inducir a confusión. La vista a que se refiere el procurador no es la definitiva de la apelación, sino esta instancia en sí. El 5 de enero de 1856 la sala declara conclusos los autos y se convoca «al relator para sentencia, citadas las partes». Lamentablemente, no conocemos la sentencia dictada en revista, pues de las siguientes páginas únicamente se conservan algunos márgenes, aunque, vista la dictada en apelación y las que se estaban dictando en el otro proceso, y que veremos a continuación, no creemos que contuviera motivación jurídica alguna ni referencia a los escritos en derecho.

\section{III.2. Sobre sucesión en el vínculo de D. Carlos Ramírez de Arellano}

Hemos dicho que del legajo consultado se desprende la existencia de un segundo procedimiento paralelo al anterior, con sus sentencias de primera instancia, apelación y suplicación, y para el que disponemos de los apuntamientos en los grados de apelación y súplica. Pues bien, las alusiones durante este proceso a estos apuntamientos y a las alegaciones jurídicas son igualmente interesantes y, por lo mismo, he considerado que también que vale la pena comentar y transcribir algunas de ellas ${ }^{40}$.

cientos cuarenta y nueve lo confirmamos, y en lo que no, lo revocamos.»; ARV, EC, 1854, núm. 19, fol. 322.

${ }^{39} \mathrm{ARV}, E C, 1854$, núm. 19, fol. 407.

${ }^{40}$ En la sentencia de primera instancia apelada, de 16 de abril de 1852, brilla por su ausencia cualquier tipo de fundamentación: «Don Juan Gómez Ynguanzo, juez de primera instancia de esta ciudad, cuartel de San Vicente: En el pleyto civil entre partes [...], sobre que se declare a su tiempo que el vínculo fundado por por don Carlos de Arellano en el testamento obrante en autos corresponde al primero como varón desendiente del último posehedor legítimo de insinuada vinculación, con- 
El ramo de apelación se inicia con el mandato de la sala «Al relator para la formación del apuntamiento», de 14 de julio de 1852 . Tras los pertinentes escritos de las partes, reiterativos en cuanto a los razonamientos fácticos y también jurídicos, y en los que finalmente concluyen para definitiva, el 5 de noviembre de 1853 «se han estos autos por conclusos, y citadas las partes vuelvan al relator para definitiva», señalándose para la vista definitiva el día 15. Pero el 12 se presentaba la siguiente petición:

Don Miguel Gordó, en nombre de don Antonio Peris, administrador de las fundadas por la marquesa viuda del Ráfol [...] digo: Que V.E. se ha servido señalar la vista de dicho pleito para el día 15 de los corrientes; pero considerando que el objeto del litigio es de mucha importancia, y que las cuestiones que en él se debaten son varias y de difícil discusión, porque versan sobre la inteligencia de varias cláusulas de una fundación cuyo trabajo no es fácil siempre mandarlo a la memoria, ni es dado a los letrados directores de las partes presentar sus razones en un discurso verbal, con el método y precisión con que pueden hacerlo en un escrito de derecho, y teniendo en cuenta, por fin, la mayor comodidad con que podrá V.E. estudiar el negocio para el fallo, teniendo a la vista impreso el memorial ajustado, y los escritos de las partes, en vez de fatigar su memoria con las alegaciones verbales, que habrán de durar tres o cuatro días por lo menos, en razón de ser cuatro las partes, y abrigamos la confianza de que este pensamiento será aceptado por los demás litigantes; y por ello:

Suplico a V.E. se sirva suspender la vista del pleito señalada para el día 15 de los corrientes, conceder el permiso necesario para escribir en derecho y, verificado y concertado que sea el memorial ajus-

denándose en consencuencia a la resititución de bienes, frutos y rentas a los espresados administrador y marqués de Malferit, quien reconociendo en el propio juicio al actor cuando contestaba la demanda pretende se declare igualmente que el nombrado mayorazgo correspondió por el causante de la dicha marquesa a Don Joaquín Roca y Castelví [...]. Fallo por su resultado que absolvía y absuelvo de la demanda propuesta por el Barón de Cenija a los demandados, declarando por lo que hace a la reconvención del Marqués de Malferit que a éste toca, corresponde y pertenece la vinculación erigida por D. Carlos de Arellano por el finamiento sin succesión de D. Joaquín Roca Castelví y muerte de D. Miguel Castelví sin hijos varones, condenando en consecuencia a D. José María Verza como administrador de las fundadas por la marquesa difulta del Ráfol y a sus herederos demandados también para en su caso a que en el plazo de quince días dejen a disposición del citado marqués los bienes que aquel administra y forman, constituyen y componen la mitad de los del vínculo espresado, condenándole igualmente al abono de frutos o rentas desde que fue contestada la petición puesta por el D. Pascual contra el demandante y demás demandados, pagando cada uno las costas de su instancia y por mitad las comunes.»; ARV, EC, 1854, núm. 19, fol. 467 de su ramo. 
tado e impreso a costas comunes, conceder a las partes el término legal para presentar los alegatos; y será justicia que pido ${ }^{41}$.

Respecto al proceso anterior, en éste parece pedirse una diferente secuencia temporal para la vista, apuntamiento, alegaciones jurídicas y resolución. En aquel proceso se había seguido este orden, acorde con la Novísima. La tramitación de éste nos hace pensar que aquí la vista se celebra después de la redacción y presentación del memorial y de las alegaciones. La petición para escribir en derecho se presenta tras el señalamiento y la citación al relator y a las partes para la vista definitiva. Y el mismo día en que se presenta esta petición, la sala suspende la celebración de la vista y traslada la petición a las otras partes. En principio, la de este proceso sería una secuencia más lógica, en la medida en que se posibilitaba una vista con un debate de mayor calado jurídico. Pero veremos que esto no está tan claro.

El 24 de noviembre una segunda parte argumenta en contra de la presentación de los informes jurídicos:

Don José Dalmáu [...] esta pretensión se funda en la importancia del litigio en que las cuestiones son varias y de difícil resolución, y en la mayor comodidad de V.E. y dificultad de sostener verbalmente los derechos de las partes. Estas razones, sin embargo, en mi humilde concepto no bastan para que V.E. acceda a semejante pretensión. La cuantía del pleito no lleva consigo la exigencia de una alegación impresa, porque lo mismo puede defenderse verbalmente un pleito en el que se litigue sobre mil que sobre cien mil duros, y nunca dejará de ser igual la cuestión, en uno que en otro caso; esta razón es por lo mismo inadmisible en los tribunales.

La dificultad del pleyto no puede tampoco autorizar un gasto innecesario porque aquí no existe esa dificultad en cuanto a mi representado, y el negocio no solo no es arduo, sino que debe calificarse de sencillo y de fácil espedición. En la sucesión de un vínculo en el que están espresamente llamados los hijos naturales del poseedor, con preferencia a las hijas legítimas, viene a demandar el descendiente de un hijo de don Basilio Guzmán, que se haya legitimado, cuando dicho don Basilio poseyó y no tuvo otro hijo. Véase cuán sencilla es la cuestión y cuán fácil de discutir y resolver.

${ }^{41} \mathrm{ARV}, E C, 1854$, núm. 19, fol. 91. Veáse el mismo razonamiento, pero transcrito en la propia alegación jurídica: Memoria jurídica a favor de la señora $D .{ }^{a}$ María del Carmen Madriguera y Cot, González de Varea ...; AICAV, R-6149, Barcelona, 1827, pág. 1, en donde se dice: «No siendo posible ceñir a un informe en voz, solicitado por [...], todas las reflecciones legales que ecsige la presente controversia, sin riesgo de omitir, por olvido, alguna de ellas, ha pedido e impetrado la demandada [...] de la sabiduría y rectitud de esta Real Audiencia en la segunda sala civil de justicia, la facultad de escribir en derecho». 
Con lo que hemos espuesto queda en nuestro concepto destruido cuanto se alega para sostener la pretensión deducida; no será inoportuno sin embargo elevar a la consideración de V.E. que cualquiera interesado puede reclamar el concierto del apuntamiento abonando las costas que en ello se causen y ningún inconveniente tenemos por nuestra parte, en que tal concierto se verifique, siempre que sea con la insinuada condición, empero el concierto no lleva en pos de sí la necesidad de escribir en derecho y nos oponemos a que se conceda el permiso reclamado.

En esta atención, suplico a V.E. que accediendo al cotejo del apuntamiento a costas de la parte que lo reclama, se sirva V.E. denegar el permiso para escribir en derecho ${ }^{42}$.

Estos escritos nos confirman algunas hipótesis planteadas en el proceso anterior. Por una parte, el concierto de los hechos y especialmente su impresión, suelen costearse por la parte que lo solicita, cuando no es la sala la que motu proprio lo ordena. Por otra, este concierto no debe ser una decisión adelantada ni debe presuponer el permiso para escribir en derecho; el comentario interesado de este procurador, no obstante, parece indicar que así solía suceder. El 3 de diciembre, una tercera parte propone una solución intermedia:

Don Antonio Ayala [...] en medio de esta diversidad de opiniones lo que yo creo es que las dos partes que han espuesto hasta ahora tienen razón y, por consiguiente, que ésta se halla repartida entre aquéllas. Con efecto la tiene don José Dalmáu, porque la única cuestión que interesa a su principal es en verdad sencilla y fácil de resolver, estando casi reducida a si don Gaspar Guerau fue hijo natural de don Basilio o fue adulterino o bastardo; y realmente en un discurso verbal y de poca duración puede demostrarse hasta la evidencia que el tal don Gaspar fue adulterino, o cuando menos que no fue natural, y que el barón de Cenija no tiene derecho alguno al mayorazgo en que pretende suceder.

Y tiene también razón don Miguel Gardó, porque la cuestión que versa entre el administrador de las fundadas por la marquesa del Ràfol y sus herederos de una parte, y de otra el marqués mi representado, es de distinta índole y de diferente naturaleza, porque para comprender y resolver con acierto si el mayorazgo cuando murió el padre de dicha marquesa debió pasar a ésta o al marqués de Malferit, que es la otra cuestión que aquí se agita, hay necesidad de estudiar detenidamente una cláusula de fundación, y aunque el derecho de mi principal se hace incontrovertible, es ésta una verdad para cuya demostración es indispensable emplear un largo raciocinio, comentando y explicando aquella cláusula y combatiendo además la inteligencia en mi concepto errada, que le dan el administrador de las fundadas por la marquesa del Ràfol y los herederos de la misma.

${ }^{42}$ ARV, EC, 1854, núm. 19, fol. 93. 
De manera que a mi modo de ver es fácil informar verbalmente en cuanto a la cuestión concerniente al barón de Cenija, pero arduo, difícil y arriesgado el hacerlo sobre la otra que queda referido.

Yo, pues, en consideración a todo esto no formulo pretensión alguna determinada, ni hago otra cosa que dejar al juicio de V.E. la solución del problema pendiente, sometiéndome a lo que sobre el particular se resuelva ${ }^{43}$.

Finalmente, el 14 de diciembre la cuarta parte se muestra más categórica:

Don Ignacio Torres [...] pido a V.E. acceda de lleno a la solicitud de don Miguel Gardó. El negocio centraría dos grandes cuestiones de derecho dignas de discutirse por todos los medios admitidos por la ley y la práctica para esclarecer los puntos controvertidos y para facilitar la recta administración de justicia. Si tratándose de la succesión en la mitad de un gran vínculo, si agitándose una cuestión de cualidad succesoria con uno de los pretendientes y otra cuestión de cláusula entre los demás aspirantes, no se concerta e imprime el memorial o estracto y no se escribe en derecho, ¿̇en qué otros espedientes podrá ya tener cabida este medio de ilustrar al tribunal? Espero, pues, que V.S. se persuada de la buena razón con que pide Gardó que ninguno de los otros litigantes contradice fundadamente, y en este concepto,

Suplico se sirva acceder al concierto e impresión del estracto y dar su permiso para escribir en derecho, y así será justicia ${ }^{44}$.

Previa citación de las partes, el 24 de enero de 1854 se celebra vista, a la que acuden los procuradores, que no los abogados, resolviendo la sala:

Con el fin de que las partes escriban en derecho a su tiempo, practíquese el concierto e impresión del apuntamiento a costas, por ahora, de la administración fundada por la marquesa viuda del Ràfol, del marqués de Malferit y de don José Caro, como padre y legal administrador de don Miguel Caro y Baciero ${ }^{45}$.

Es decir, se aprueba la presentación de los escritos en derecho, a cuyo efecto se había de proceder a la redacción del apuntamiento a cargo de los interesados ${ }^{46}$. Y todo ello antes de la celebración de la vista definitiva.

${ }^{43}$ ARV, EC, 1854, núm. 19, fol. 95.

${ }^{44}$ ARV, EC, 1854, núm. 19, fol. 99.

${ }^{45}$ ARV, EC, 1854, núm. 19, fol. 103v.

${ }^{46}$ Los párrafos finales de este apuntamiento también son bastante esclarecedores: «63. Conferido traslado y autos a los demás litigantes, con suspensión de la vista. 64 . El barón de Zenija se allanó al cotejo del apuntamiento a costas de la parte que lo reclamaba; y pidió se denegase el permiso para escribir en derecho. 65. El marqués de Malferit, sin formular pretensión determinada, lo dejó al juicio de la sala. 66. Don José 
Huelga decir que el apuntamiento no contenía mención alguna a disposiciones jurídicas, para las que se reservaban los escritos en derecho. Y, como en el anterior proceso, los autos no dejan constancia del cotejo de los hechos por las partes; en este caso, ni siquiera por parte del tasador. El 12 de julio de 1854, y «dada cuenta en sala de estar practicada la impresión del apuntamiento, los señores del margen dijeron: se concede a las partes el término de un mes para escribir en derecho y, transcurrido, con las alegaciones o sin ellas, dese cuenta ${ }^{47}$.

Dos diferencias relevantes encontramos respecto a la tramitación anterior. Mientras aquí se disponía de un mes entero para redactar las alegaciones, allí, dentro del mismo mes se debía imprimir el apuntamiento para pasar a continuación a escribir las alegaciones; obviamente, el tiempo para preparar éstas iba a ser menor. Y no consideramos que el debate jurídico del anterior proceso era, en absoluto, de menor envergadura. Es más, el 9 de agosto, la parte más interesada de este segundo proceso en escribir las alegaciones solicita, y la sala concede a todas ellas, quince días más para presentarlas ${ }^{48}$. Y a finales de mes se solicita y se concede una nueva ampliación del término; en este caso, de diez días más ${ }^{49}$.

Caro pidió se accediese al concierto e impresión del estracto y al permiso para escribir en derecho. 67. Y acusada la rebeldía a los estrados señalados a don Joaquín Mercader. 68. La sala, por decreto de 24 de enero último, con el fin de que las partes escribieran en derecho a su tiempo, mandó se practicase el concierto e impresión del apuntamiento a costas, por ahora, de la administración fundada por la marquesa viuda del Ràfol, del marqués de Malferit y de don José Caro, como padre y legal administrador de don Miguel Caro y Baciero. 69. Se han guardado las leyes que arreglan el procedimiento; y los actos y diligencias se han estendido en la clase de papel y en los términos prevenidos en el real decreto de 8 de agosto de 1851 . Y con asistencia de los letrados y procuradores que firman, se ha practicado el concierto del apuntamiento.»

${ }^{47}$ ARV, EC, 1854, núm. 19, fol. 105.

48 «Miguel Gordó suplica que el letrado que suscribe fue nombrado de la Junta de Gobierno creada con motivo del alzamiento nacional contra el ministerio del Conde de San Luis, y ha estado dedicado noche y día al despacho de los negocios públicos hasta el día 5, por lo que, por no haber podido dedicar un momento a la redacción del papel en derecho que debía presentar dentro de los treinta días que le concedieron a las partes, pide se le conceda nuevo tiempo»; ARV, EC, 1854, núm. 19, fol. 107. Ese mismo día la sala le concede quince días más «para escribir en derecho», pasados los cuales Gordó solicita otros 10 ó 12 para la impresión, a lo que la sala de nuevo accede con 10 días (fol. 109).

49 «Que el letrado que suscribe, a pesar de sus incesantes ocupaciones, ha terminado el escrito en derecho para cuyo trabajo se prorrogó el término quince días, pero ocurre que se necesita todavía el tiempo necesario para la impresión, y en este concepto calculando que se necesitan diez o doce días»; ARV, EC, 1854, núm. 19, fol. 109. 
Pero la diferencia más importante respecto al primer proceso, insistimos, es que mientras que allí la vista definitiva se celebra con anterioridad a la presentación del apuntamiento y las alegaciones, con la asistencia de procuradores y abogados, aquí parece celebrarse después de haberse presentado estos escritos. Es decir, que pudiendo los magistrados consultar las disquisiciones jurídicas en las alegaciones, holgaba la asistencia a la vista definitiva de los abogados y, por lo visto, también de los procuradores. Así pues, el 29 de noviembre, y una vez «hecho presente por el relator el estado de este pleito y habérsele entregado por los procuradores de las partes las alegaciones en derecho", se señala para la vista definitiva el 4 de diciembre de 1854. En ella «se vio con asistencia de escribano de cámara, portero y alguacil, habiendo durado menos de una hora». El mismo día e inmediatamente a continuación se acuerda que el relator repartiera el apuntamiento con las alegaciones en derecho, «las cuales, dentro el término de los treinta días de la ley, podrán adicionarlas hasta el número de hojas que la misma permite; procediéndose a pronunciar la sentencia dentro de los sesenta prevenidos en el Reglamento Provisional para la Administración de Justicia ${ }^{50}$.»

Y es aquí donde nos surgen las dudas sobre la vista que debemos considerar definitiva, puesto que, a falta de alguna hoja de autos -cosa probable-, parece que volvemos a la misma estructura que la del proceso anterior: vista, apuntamiento, alegaciones y votación y resolución. El que la de 4 de diciembre sea considerada como la vista definitiva, aun sin la asistencia de abogados, lo corrobora el hecho de que desde ella se cuenta el término para dictar sentencia. Si se presentaron adiciones, nada dicen los autos. De nuevo, en ella no se habría contado con los informes jurídicos. Es más, en este caso ni siquiera habían participado abogados ni procuradores. Es como si la vista se limitara a una mera comprobación del correcto proceder a lo largo del pleito y no se discutiera sobre derechos.

En cuanto a la sentencia, de 17 de enero de 1855, ya sabemos que poco nos puede aclarar ${ }^{51}$. Contra ella los procuradores Dalmáu

${ }^{50} \mathrm{ARV}$, EC, 1854, núm. 19, fol. 111. Véase artículo 80 del Reglamento.

${ }^{51}$ «En el pleyto que en grado de apelación ante Nos ha pendido y pende, entre partes [...], sobre sucesión en el vínculo fundado por D. Carlos Ramírez de Arellano, Vistos: Fallamos: Que debemos absolver y absolvemos a D. Pascual Mercader y Roca, marqués de Malferit, a D. Joaquín Mercader y Roca y D. Miguel Caro y Baciero representado por su padre D. José como sucesor de la marquesa del Ráfol, y al administrador de las fundadas por la misma D. Antonio Peris, de la demanda propuesta D. José Cisternes de Oblites, antes Guerau de Arellano, barón de Zenija. Y absolvemos 
y Ayala interponen recurso de suplicación, allanándose los otros dos colitigantes. En la conclusión para definitiva de la instancia de suplicación, de 16 de agosto, Ayala pide y da por sentado que va a presentar nuevas alegaciones jurídicas ${ }^{52}$. También lo da por sentado el procurador Miguel Gordó, manifestando ser costumbre el permitirlo en la nueva instancia cuando en la anterior se ha resuelto sobre lo escrito en las alegaciones ${ }^{53}$. Igualmente está conforme con pre-

asimismo a dicho administrador D. Antonio Peris y para en su caso a D. Joaquín Mercader Roca, D. Miguel Caro y Baciero de la mutua petición deducida por D. Pascual Mercader y Roca, marqués de Malferit. En cuanto con esta sentencia sea conforme la apelada, que en diez y seis de abril de mil ochocientos cincuenta y dos dictó el juez de primera del cuartel de San Vicente de esta ciudad, la confirmamos, en la que no, la revocamos. Y declaramos que los gastos del concierto e impresión del memorial ajustado deben ser de cuenta y cargo de la administración fundada por la marquesa del Ráfol, del marqués de Malferit y de D. José Caro y Caro en la representación que interviene.»; ARV, EC, 1854, número 19, fol. 113 de su ramo.

52 «Otras varias razones que lo demuestran y lo justifican podríamos añadir, pero pues unas están alegadas en el escrito en derecho que V.E. tendrá a la vista para fallar y otras se alegarán a su tiempo por vía de adición a dicho escrito, me remito al mismo, en obsequio de la brevedad y por no repetir ideas ni palabras [...] Otrosí: en la anterior instancia se permitió alegar por escrito e imprimir las alegaciones, con lo cual se reconoció que el pleito lo merecía, y que era necesario o conveniente cuando menos para la defensa de las partes y para ilustrar las cuestiones. En este grado se ofrece a mi principal exponer nuevas razones en defensa de su derecho y refutar las alegadas en contra de su demanda, adicionando el informe escrito e impreso, y como no puede hacerlo en debida forma sin el permiso de la sala: suplico a V.E. se sirva otorgarlo y conceder plazo para verificar la indicada adición.»; ARV, EC, 1854, núm. 19, fol. $171 \mathrm{v}$.

${ }^{53}$ En su conclusión para definitiva de 10 de septiembre, pide y se manifiesta de la siguiente manera: «Después de los alegatos impresos que tuvieron presentes para el fallo los magistrados de la sala originaria, ¿qué cosa nueva de importancia se ha dicho por los contrarios para mejorar su causa y para esperar la mejora y enmienda de la sentencia de vista? Nada, absolutamente nada que pueda aprovecharles. Desconcertados completamente, apenas han tenido aliento para escribir algunas frases con desconfianza o para utilizar alguna razón de tan aparente y efímera eficacia que ni siquiera a ellos mismos les ha podido inspirar la menor confianza. Como quiera que sea, ya en mi anterior escrito del fol. 147 y siguientes se contestó lo que creíamos conveniente, si bien no hicimos más que reproducir lo que se dijo en el discurso legal impreso presentado por mi parte. Ahora en este juicio forzosamente habrán de adicionarse dichos alegatos y por lo mismo, y no habiendo de tenerse presente este escrito

para el fallo, sería inútil cuanto pudiera alegarse. El letrado que suscribe se reserva hacerlo en la edición impresa, en cuyo trabajo se hará cargo de todo cuanto en este juicio han dicho los contrarios [...]. Otrosí: La adición de los papeles en derecho es necesaria y de costumbre, y práctica observada siempre cuando los pleytos se han fallado en vista de tales alegatos. Por esta razón, y porque la parte del marqués de Malferit lo solicita para alegar nuevas razones, y porque yo también deseo sostener la sentencia de vista con las que me ha ofrecido el letrado que suscribe, estoy conforme con la petición de don Antonio Ayala.»; ARV, EC, 1854, núm. 19, fol. 175. 
sentar adición la parte representada por Ignacio Torres ${ }^{54}$. Y como lo hizo en la instancia anterior, José Dalmáu sigue oponiéndose a ello ${ }^{55}$.

Así es que el 28 de marzo la sala decide en vista incidental: «se han estos autos por conclusos y citadas las partes vuelvan al relator para la vista, y con igual citación procédase a la impresión del apuntamiento a costas por ahora de la administración fundada por la marquesa viuda del Ráfol, del marqués de Malferit y de José Caro como padre y legal administrador de Miguel Caro ${ }^{56}$. Es decir, que se accede a la impresión del nuevo apuntamiento a costa, de nuevo y "por ahora», de las tres partes que solicitan la presentación de los escritos en derecho ${ }^{57}$. Presuponemos con ello que la autorización para

${ }^{54}$ «Por parte del marqués de Malferit se han dado algunas alegaciones generales y se ha reservado lo principal, no sin conocida habilidad para la adición que medita al escrito en derecho. Esto pues, y el ver yo que por parte del administrador de las fundadas por la marquesa del Ráfol no se contradice la idea de adicionar los alegatos en derecho, me hace a mí comprender la conveniencia de guardar la misma reserva [...]. Adopto pues el medio indicado por lo que a mí toca, pero debo antes dejar sentado que no habiendo alterado nuevas pruebas el mérito y estado de las cuestiones que se ventilan, se puso ya en evidencia lo inadmisible de la demanda del barón de Zenija, y casi nada puede añadirse a lo mucho que en contra de ella se ha alegado [...] $2^{\circ}$ Otrosí: No puedo contradecir la petición del marqués de Malferit, secundada por el administrador de las fundaciones del marqués del Ráfol para adicionar el escrito en derecho. Suplico a V.E. se sirva haberme por allanado»; ARV, EC, 1854, núm. 19, fol. 217 (14 de febrero de 1856).

55 «En la instancia anterior se escribió en derecho, entonces se debatieron estensamente las cuestiones del pleyto y la parte de don Antonio Ayala y las demás que litigan pudieron alegar y alegaron todo cuanto podía concluir al sostén de sus derechos. ¿Qué razón puede haber, pues, para que ahora se permita de nuevo escribir en derecho? Ninguna, absolutamente ninguna. Y al paso que nada hay que motiva un nuevo escrito en derecho, hay por el contrario razones que aconsejan la inconveniencia de que ahora como adición a la anterior se hiciera una nueva alegación. Entonces vendrían esas dos alegaciones a formar una sola, y como la adición no podía versar sobre nada nuevo y havía de recaer sobre los mismos puntos que se havían tratado ya, resultaría una alegación tan estensa que pudiera introducir la confusión, en vez de la precisión y claridad que ha apetecido la ley al fixar los límites de esos escritos. Además, ya hemos dicho que esto sobre ser inmotivado, sobre no producir ningún bien para la defensa de los litigantes y la acertada resolución del litigio, había de ocasionar a aquéllos un nuevo gasto y una nueva dilación que debe evitarse»; ARV, EC, 1854, núm. 19, fol. 221 (3 de marzo de 1856).

${ }^{56} \mathrm{ARV}, E C, 1854$, núm. 19, fol. 223.

${ }^{57}$ El apuntamiento, breve en este caso, termina así: «13. Se han guardado las leyes que arregan el procedimiento y los actos y diligencias se han estendido en esta $3^{\mathrm{a}}$ instancia en la clase de papel y en los términos prevenidos en el real decreto de 8 de agosto de 1851 . Valencia, 12 de abril de $1856 »$. Recuérdese que el pleito no se tramitaba todavía por la Ley de Enjuiciamiento Civil. Según el régimen transitorio fijado en su decreto de aprobación, los pleitos iniciados con anterioridad a su fecha solo se sustanciarían por la $L E C$ si lo acordasen todas las partes implicadas, lo que ni siquiera se planteó en este caso. 
escribir en derecho estaba asegurada; por ello los abogados no asistirían a la vista. Señalada ésta para el 28 de mayo, "se vio con asistencia del escribano de Cámara, procurador Dalmáu, portero y alguaciles, habiendo durando menos de una hora»-obsérvese que el único procurador que asiste es el que se había negado a la presentación de las alegaciones-. A continuación, la sala acordaba conceder «permiso a las partes para escribir en derecho en el número de hojas y forma establecida en la Ley, debiendo presentar sus alegaciones dentro del término de los treinta días prevenidos por la misma y procediéndose a pronunciar la sentencia en los sesenta prefijados en el Reglamento Provisional para la Administración de Justicia» ${ }^{58}$.

De nuevo, pues, el recorrido temporal respecto a la vista y la presentación del apuntamiento y de las alegaciones es, según este orden, el mismo, el marcado por la Novísima, aunque el permiso para escribir en derecho se tomase con anterioridad. Lo bien cierto es que, tal vez por el fallecimiento de alguna parte, el 17 de octubre se vuelve a celebrar nueva vista, para inmediatamente a continuación ordenarse al relator repartir entre los señores dirimentes «el memorial ajustado y su adición, y las alegaciones en derecho y adiciones», cosa que hizo el día $20^{59}$. Entendemos que se estaba refiriendo a los memoriales de hecho y alegaciones tanto de vista como de revista, con el nombre de adiciones para esta última instancia ${ }^{60}$. Y suponemos que esta última sería la vista definitiva, pues de lo contrario los términos marcados por el Reglamento para dictar sentencia -sesenta días desde la vista- no se cumplirían. La sentencia en suplicación, de 18 de noviembre de 1856, seguía la tónica de la praxis tradicional; lacónica y escueta. Eso sí, hacía recaer sobre las partes absueltas los gastos de impresión del memorial ajustado ${ }^{61}$.

58 ARV, EC, 1854, núm. 19, fol. 230. Inmediatamente anterior es el siguiente apunte: «Se vio con asistencia del escribano de cámara, procurador Dalmáu, portero y alcuaciles, habiendo durando menos de una hora», sin que entendamos aquí la asistencia de este procurador. El 1 de julio el relator escribía: «En este día se han repartido a los señores ministros que vieron el presente pleyto el memorial ajustado y su adición, y las alegaciones en derecho y adiciones del marqués de Malferit, de la baronesa de Zenija y del administrador de las fundadas por la marquesa del Ráfol; no habiéndose presentado por parte de D. Miguel Caro y Baciero» (fol. 235v).

${ }^{59}$ ARV, EC, 1854, núm. 19, fol. 242v.

${ }^{60} \mathrm{ARV}$, EC, 1854, núm. 19, fol. 242. Según nota del relator de 20 de octubre: «Derechos de reconocimiento, apuntamiento y sentencia: doscientos treinta y cinco reales. Del Ador. D. Antonio Peris: por el reconocimiento de las alegaciones y repartirlas: ciento noventa y cuatro reales. Del marqués de Malferit por el mismo concepto: ciento veinte y cuatro reales. De la baronesa de Zenija: ciento cincuenta reales».

${ }^{61}$ «Visto: Fallamos: Que debemos confirmar y confirmamos la sentencia suplicada que en diez y siete de enero de mil ochocientos cincuenta y cinco pronunciaron los 


\section{BREVE EPÍLOGO}

La sucesión de trámites vista en estos dos procesos se confirma en la Ley de Enjuiciamiento Civil, que, dicho sea, tampoco es mucho más clara que la normativa histórica. Ello permitiría a cada audiencia continuar actuando, en cada caso, según su mejor entendimiento, al menos los primeros años. La doctrina también mostrará diferentes y flexibles pareceres. Mientras que Hernández de la Rúa insinuaba que «supuesto que la alegación en derecho escrita hace innecesaria, o más bien suple la vista», Pedro LóPEz Claros, práctico y abogado del colegio de Madrid, opinaba que los abogados, al solicitar escribir en derecho, podían pedir que la vista se suspendiera por un determinado término; es decir, que informes y vista convivirían. De la Serna y Montalbán opinaban que, «conclusos los autos y después de visto el pleito, suelen los abogados hacer información o escribir papel en derecho ${ }^{62}$. Disparidad de opiniones.

Al margen de la compleja reconstrucción a que hemos procedido, todo indica que, dada por supuesta la redacción y presentación de las alegaciones jurídicas, los letrados no necesitaban comparecer en la vista definitiva. Aunque la legislación histórica parece establecer que era en ella donde se decidía la redacción, impresión y presentación de estos informes, por economía procesal, especialmente a favor de las partes, se intentaba evitar lo que no iban a ser más que duplicidades. En el mismo sentido se manifestaba la Instrucción del Marqués de Gerona, cuando en el artículo 63 declaraba potestad de las partes el presentar o no abogado para la defensa oral en el acto de la vista, pudiendo substituirla, en su caso, por un alegado firmado por aquel letrado. Esta última previsión, en forma de

señores de la sala segunda de esta audiencia, por la que se absolvió a don Pascual Mercader y Roca, marqués de Malferit, Joaquín Mercader y Roca y a [...] de la demanda propuesta por D. José Cisternes de Oblites [...]. Y se absolvió asimismo a dicho administrador don Antonio Peris y para, en su caso, a don Joaquín Mercader y Roca, marqués de Malferit. Y declaramos que los gastos de la impresión del memorial ajustado en esta instancia deben ser de cuenta y cargo de la administración fundada por la marquesa del Ráfol, del marqués de Malferit y del conde de Rótova en la representación que interviene.»; ARV, EC, 1854, núm. 19, fol. 243 de su ramo (18 de noviembre de 1856).

${ }^{62}$ Hernández de la Rúa, V., Comentarios a la Ley de Enjuiciamiento Civil, 5 vols., Madrid, 1856, IV, pág. 90; LóPEz CLAROS, P., Diccionario Teórico-Práctico del Enjuiciamiento Civil, Madrid, 1856, pág. 87; y Gómez DE LA Serna, P. y Manuel MonTABÁn, J., Tratado Académico-Forense..., II, pág. 190. La doctrina del momento debate sobre la oralidad o escritura del proceso. Y si los autores no parecen mostrar una gran querencia por las alegaciones jurídicas, Hernández de la Rúa, por el contrario, tal vez sea la excepción (Comentarios a la Ley..., IV, pp. 87 ss. 
substitución, tal vez pretendiese terminar con las alegaciones jurídicas; la escasísima aplicación de la Instrucción nos impide mayores concreciones. De nuevo, es posible que fuera la práctica de cada audiencia la que finalmente decidiese en cada caso, especialmente en estos momentos, ante unos escritos en franco declive en todos los sentidos. Y a pesar de este declive, la Ley de Enjuiciamiento Civil regulaba las alegaciones jurídicas como nunca hasta entonces se había hecho.

La justicia decimonónica de la primera mitad del siglo XIX, pues, no pasa en ningún momento por erigir un nuevo sistema jurídico-procesal -si es que lo había y era posible-, sino que se centra en renovar y actualizar lo ya existente a través de retoques más o menos puntuales. En unos momentos en que los viejos textos se están substituyendo o se intentan substituir por otros nuevos -se querían códigos-, más seguros y acordes a la nueva realidad, la normativa procesal no parece tener grandes pretensiones, más allá de la organización del Tribunal Supremo y, en concreto, de su recurso de casación. En materia civil, y desde la justicia ordinaria, las reformas procesales parecen ceñirse a cuestiones meramente procedimentales (son significativos los debates sobre plazos y términos). El verdadero calado jurídico del proceso civil apenas experimenta modificaciones de relevancia. Algo tan significativo -o tal vez no- como el propio discurso jurídico de los letrados, así como el proceder igualmente jurídico de los jueces, apenas se cuestiona hasta la segunda mitad del siglo.

Pero todo ello no obsta para que, andando el tiempo, se vaya configurando una práctica forense cada vez más distanciada de esquemas pretéritos. En plena espiral sustitutoria de normas, sustantivas y procedimentales en según qué ámbitos, en el proceso civil se va infiltrando, lenta y tranquilamente, un nuevo estilo, una nueva manera de comunicación entre el juez y las partes, una nueva intercomunicación. Siendo los instrumentos los mismos -proceso y trámites apenas sufren modificaciones de consideración-, la redacción y el contenido de los escritos muestran síntomas de evolución. Nos referimos, fundamentalmente, a la participación de los letrados en el proceso de una manera mucho más directa a los ojos de los operadores jurídicos e, incluso, de la propia comunidad; a la posibilidad de las partes, en esencia, de mostrarle al juzgador las normas jurídicas que tenían que ser consideradas en cada caso. Y, en sentido inverso, y más tarde en el tiempo, mostrando también el juez a las partes y a la misma comunidad la norma que, definitivamente, era la que recogía y debía resolver la cuestión debatida. 
Si esto segundo venía revestido de un mayor calado legal y político, por la consideración político-social del juez, el cambio en los escritos de los letrados se llevará a cabo, de facto, con anterioridad incluso a su mismo reconocimiento, permisión o prescripción por el ordenamiento jurídico. El pleito de la duquesa de Almodóvar es un buen ejemplo. En él se aprecian transgresiones notorias de la tradición, tales como la de copiar textualmente las disposiciones legales en distintos escritos procesales, cosa impensable hasta ahora. Paralelamente, y respecto al contenido estrictamente jurídico de los mismos escritos procesales, y también de los informes en derecho finales, se da por finiquitado el viejo mos italicus y se impone el legalismo de nuevo cuño, de derecho nacional.

En definitiva, y esto es importante, la justicia, en mayúscula y también en cada una de sus materializaciones individuales a lo largo del proceso, ya no será solo una cuestión exclusivamente formalista y ritual, basada en un procedimiento igualmente formalista en que la escrupulosa observación de todos y cada uno de sus trámites fuera la mejor garantía de la rectitud y acierto en el fallo. La justicia empezará a ser también -se pretende que sea- una cuestión de contenidos. Como se refleja en el proceso que hemos analizado, abogados y jueces se permiten la licencia de interactuar con la ley, y de modelar el procedimiento según la oportunidad del caso. Es una actitud menos pasiva y distante que antaño. Es, si se quiere, respecto a los jueces, una nueva manifestación de la discrecionalidad, entendida ahora como adaptación a una nueva realidad y a unas nuevas ideas que se sabían transitorias - tal vez, incluso, dirigida a un fin tan concreto como podía ser el del mayor perfeccionamiento de la resolución-. Esta transitoriedad permitía, tal vez aconsejaba, una mayor soltura ante la ley, tanto para juez como para las partes, mientras no se dispusiera de una regulación procesal ya definitiva.

La segunda mitad del siglo, con la Ley de Enjuiciamiento Civil de 1855, avanzará en este camino, ordenando, consolidando y dando cobertura legal a recientes prácticas que hasta ahora no habían hecho más que apuntar en el proceso. Porque, como siempre, los hechos se adelantaban al derecho. 